Est Ag 40 (2005) 329-370

\title{
El rostro africano de Cristo en los modelos de Charles Nyamiti y Laurenti Magesa
}

"Solamente podemos conservar la verdad de la fe haciendo teología sobre Jesucristo y haciéndola siempre de nuevo", decía K. Rahner1. Hoy estamos asistiendo a una auténtica "era cristológica" con una proliferación de publicaciones sobre Cristología sin precedentes en toda la historia del cristianismo. En esta línea el contexto del cristianismo africano hace tiempo que ha dejado de ser una excepción.

Cuando en 1956 un grupo de teólogos africanos del área francófona se planteaba la posibilidad y la necesidad de una teología africana ${ }^{2}$, no podían sospechar que apenas medio siglo después, no sólo ha nacido y se ha ido desarrollando una rica y plural cristología, sino que en la actualidad goza de un estatuto propio, científicamente reconocido, y con excelentes perspectivas de futuro. Recogiendo el sentir manifestado ya en 1974 durante un encuentro ecuménico celebrado en Accra (Ghana), la cristología es, sin duda, la disciplina teológica a la que han prestado una atención prioritaria los teólogos africanos. El presente estudio quiere dar fe de ello.

Charles Nyamiti y Laurenti Magesa son dos teólogos católicos del África Oriental y los principales exponentes de la teología tanzana contemporánea ${ }^{3}$. Al primero se le suele citar entre los pioneros de la teología africana de la inculturación. Mientras que el segundo representa a la nueva generación de teólogos de la liberación del África negra.

Junto a algunas de las contribuciones de los autores más destacados, que se citan en las notas, para el análisis de las cristologías africanas nos

${ }^{1}$ K. RAHNER, Curso fundamental sobre la fe, Barcelona 1979, 254.

2 Cf. AA.VV., Les prêtres noirs s'interrogent, Paris 1957. Los autores africanos consideran hoy esta obra como el punto de partida de la teología africana contemporánea, en su dimensión específicamente autóctona.

${ }^{3}$ C. Nyamiti es doctor en Teología (Lovaina) y en Música (Viena). L. Magesa tiene también dos doctorados en Filosofía y Teología (Ottawa) y se ha especializado en cuestiones de teología moral. Ambos son sacerdotes y docentes de la Facultad de Teología de la Universidad Católica de África del Este (CUEA) en Nairobi (Kenia). 
hemos guiado por las principales obras de consulta sobre la materia, fruto del diálogo y la colaboración entre los especialistas ${ }^{4}$. En el estudio de las fuentes de Nyamiti hemos privilegiado aquellos trabajos explícitamente cristológicos ${ }^{5}$, recurriendo solamente de forma esporádica a otras obras del autor. En el caso de Magesa, en cambio, dado que su cristología está más fragmentada entre sus escritos, hemos optado por tratar de recomponerla a partir de sus principales publicaciones 6 . Como literatura complementaria también nos servimos de algunos de los estudios existentes que proporcionan una visión de conjunto de la temática que nos ocupa?

\section{Hacia una cristología en contexto africano: entre la inculturación y la liberación}

Para la comprensión crítica de la cristología en contexto contemporánea, es importante asumir el hecho de que ya en el ámbito del NT no existe una interpretación unívoca de la persona de Jesucristo. Conviven varias

\footnotetext{
${ }^{4}$ La primera obra colectiva sobre el tema surgió en el África francófona (F. KABASÉLÉ, ed., Chemins de la christologie africaine, Paris 1986). Poco después, fruto de un simposio ecuménico de los teólogos del África Oriental, apareció una publicación de similares características (J.N.K. MUGAMBI - L. MAGESA, eds., Jesus in African Christianity. Experimentation and Diversity in African Christology, Nairobi 1989). Finalmente en R.J. SCHREITER, ed., Faces of Jesus in Africa, New York 1991 se recoge una selección de las mejores aportaciones de las dos publicaciones precedentes.

5 C. NyAMITI, Christ as our Ancestor. Christology from an African Perspective, Gweru 1984; "Christ's ministry in the light of African tribal initiation ritual": African Christian Studies 3 (1987) 65-87; "African Christologies Today" en Jesus in African Christianity, 17-39 (= R. SCHREITER, ed., Faces of Jesus in Africa, 3-23); "The Incarnation viewed from the African understanding of person": African Christian Studies 6 (1990) 3-27; "Contemporary African Christologies: Assessement and Practical Suggestions" en R. Gibellini, ed., Paths of African Theology, London 1994, 62-77.

6 L. MAGESA, "Christ the Liberator and Africa Today" en Jesus in African Christianity, 79-92 (= R. ScHREITER, ed., Faces of Jesus in Africa, 151-163); "Human Rights in the Church in Africa" en J.N.K. MugAmBI - L. MAGESA, The Church in African Christianity. Innovative Essays in Ecclesiology, Nairobi 1990, 89-110; "Has the Church a role in politics?" en AA.VV., Towards African Christian Liberation, Nairobi 1990, 69-85; "Christology, African Women and Ministry": African Ecclesial Review 38 (1996) 66-88 (= www.sedos.org/english/magesa.htm); "From Privatized to Popular Biblical Hermeneutics" en H.W. KINOTI - J.M. WALIGGO, eds., The Bible in African Christianity. Essays in Biblical Theology, Nairobi 1997, 25-39.

${ }^{7}$ Cf. S.I. MungA, Beyond the Controversy. A Study of African Theologies of Inculturation and Liberation, Diss. University of Lund 1998; V. KUSTER, The Many Faces of Jesus Christ. Intercultural Christology, New York 2001; D.J. GoERGEN, "The Quest for the Christ of Africa": African Christian Studies 17 (2001) 5-51; D.B. StINTON, Jesus of Africa: Voices of Contemporary African Christologies, New York 2004.
} 
cristologías, fruto a su vez de una selección específica de la "memoria" sobre Jesús, con las que las comunidades apostólicas querían responder a cuestiones concretas (de carácter misionero, catequético o litúrgico) de su contexto cultural específico a la luz de la experiencia pascual. Cada generación cristiana, temporalmente, como cada Iglesia local, espacialmente, siempre está llamada a entrar en el "proceso hermenéutico". Para la cristología ello implica partir de los problemas que la situación sociocultural presenta hoy a la vida de fe (contexto) para enfocarlos a la luz de la persona y la obra de Jesús (texto), y regresar tras esa iluminación, de nuevo, a la vida concreta y sus problemas (contexto).

Mientras que los métodos cristológicos deductivos (dogmáticos o escolásticos) apenas valoran la relación de la memoria y la tradición cristianas con los diversos contextos sociales, culturales o políticos, para la cristología contextualizada este es un dato fundamental a tener en cuenta. Sobre todo a partir de la segunda mitad del siglo pasado esta problemática ha sido explorada sistemáticamente por numerosos autores desde diferentes ámbitos geográficos y culturales.

En el ámbito del llamado "tercer mundo", el contexto de la reflexión cristológica está fuertemente condicionado por la común situación de violencia, miseria e injusticia que padece la gran mayoría de la población. Ahora bien, entre los diversos continentes se aprecian también acentos particulares que interpelan a la hora de hacer una cristología en contexto. Así, mientras que en América Latina, constituida por grandes poblaciones cristianas, el desafío de la cristología consiste sobre todo en la liberación integral del hombre (cristología de la liberación); en el mundo africano, la diversidad cultural es en primer lugar una provocación a llevar a cabo una tarea de inculturación (cristología de la inculturación); y en el contexto asiático, caracterizado por la coexistencia de pequeñas minorías cristianas con grandes mayorías de otras tradiciones religiosas, la prioridad o urgencia cristológica radica especialmente en el diálogo interreligioso (cristología del pluralismo religioso $)^{8}$.

Sin embargo, para evitar falsas generalizaciones, hay que notar que en el caso particular del África subsahariana, en realidad, no sólo se ha desarrollado el modelo de la inculturación, sino también el de la liberación. No así, hasta ahora, el interreligioso a pesar de la presencia plurisecular de las religiones tradicionales y de la creciente influencia del Islam en la actualidad.

${ }^{8}$ Cf. J. DupuIs, Who do you say I am? Introduction to Christology, New York 1994, 9-10. 
En efecto, al margen tanto de las cristologías no cristianas (religiones tradicionales africanas) como de las cristologías no sistemáticas ("Iglesias independientes") ${ }^{9}$, según C. Nyamiti, la teología africana contemporánea ha producido hasta la fecha dos tipos de cristologías: cristologías de la inculturación y cristologías de la liberación ${ }^{10}$.

\subsection{Cristologías de la inculturación}

Ya para el Concilio Vaticano II la historia de la evangelización cristiana fue, y sigue siendo, un continuo proceso de diálogo con las culturas. Como todo intercambio vital ello requiere dos interlocutores en un movimiento de doble dirección. Una cristología "inculturada" exige, por un lado, el esfuerzo de toda la comunidad cristiana (criterio eclesiológico) por "encarnar" el misterio de Cristo en el lenguaje, los rasgos culturales y la experiencia vital de los pueblos, siempre al servicio de la persona humana (criterio antropológico). Pero también, por otro lado, el saber discernir y acoger los elementos culturales y religiosos que quizás pueden contribuir a iluminar aspectos ocultos o no debidamente desvelados del rostro de Cristo (cf. GS 44b; 58bc).

Es "cristiana" toda cultura en la que Cristo no es un extraño, en la que las comunidades cristianas descubren a Cristo por los caminos y a través de las fuentes de sus propias culturas. Según Nyamiti, las fuentes de la "teología africana" son la memoria cristiana y la situación africana. La memoria cristiana está constituida no sólo por la Escritura, sino también por la Tradición y el Magisterio oficial de la Iglesia, mientras que la "situación africana" hace referencia a las expresiones culturales y religiosas propias, tanto del pasado como del presente ${ }^{11}$. En el contexto africano se reconoce-

\footnotetext{
${ }^{9}$ Dentro de la variedad y multiplicidad de movimientos religiosos surgidos en el continente africano a lo largo del siglo pasado, se conocen como "Iglesias independientes africanas" aquellas que, autodenominándose cristianas, han nacido de la separación de otra Iglesia o confesión cristiana, o bien han sido fundadas en África al margen de ellas como una nueva entidad religiosa, por iniciativa y bajo la guía de líderes africanos, y originariamente para los africanos. Cabe distinguir dos grupos entre las iglesias independientes africanas: las de tipo "etíope" y las "profético-curativas". A este último grupo pertenecen la gran mayoría de las iglesias independientes actuales. Sobre todo en las regiones del sur de África constituyen comunidades a imagen de las comunidades cristianas primitivas que se conocen como "Iglesias sionistas". Sobre el origen de las diversas denominaciones, cf. S. HAYES, "The African Independent Churches: Judgement through terminology?": Missionalia 20 (1992) 139-146.

10 Cf. C. NyAMITI, "African Christologies Today", 17-39; "Contemporary African Christologies: Assessement and Practical Suggestions", 62-77.

11 Cf. Id., "My Approach to African Theology": African Christian Studies 7 (1991) 39.
} 
rá a Cristo sólo a través de las categorías de pensamiento propiamente africanas y en un lenguaje apropiado y significativo para esos pueblos, porque el salto de la fe, como la gracia, no destruye la naturaleza, sino que la plenifica.

El modelo de la inculturación recibió su espaldarazo decisivo con el discurso de Pablo VI a los obispos africanos en Kampala (Uganda) en Julio de 1969 en el que les proponía un "cristianismo africano"12. Este modelo quiere dar una expresión africana a la fe cristiana y se propone la tarea de integrar el cristianismo en la vida y la cultura de los pueblos africanos. Por un lado, se trata de una nueva comprensión del contenido de la fe cristiana en el contexto de la realidad africana, y por otro, de una mirada renovada sobre esa misma realidad a la luz de la fe cristiana. Haciéndose eco de la enseñanza de su predecesor, Juan Pablo II ha expresado esa doble exigencia en los siguientes términos:

Las comunidades eclesiales en formación, inspiradas por el evangelio, podrán expresar progresivamente la propia experiencia cristiana en modos y formas originales, de acuerdo con las propias tradiciones culturales, siempre en sintonía con las exigencias objetivas de la misma fe (Redemptoris Missio 53).

Mientras que algunos autores cristianos africanos se mueven todavía en la línea de la "adaptación"13, Nyamiti se identifica personalmente con la corriente mayoritaria que ha optado decididamente por repensar el mensaje cristiano en las categorías del contexto cultural africano ${ }^{14}$.

Entre los teólogos africanos que siguen el modelo de la inculturación, Nyamiti identifica dos modos de proceder. Uno deductivo, que a partir de la cristología bíblica trata de elaborar un discurso cristológico que responda a la situación cultural africana; y otro inductivo, que elabora la cristología desde la realidad actual africana a la luz de la Escritura. Dentro de las

12 Cf. $A A S 61$ (1969) 573-578. Pablo VI se refería a la posibilidad de expresar la fe en un "lenguaje" pluriforme y original de acuerdo con la propia cultura: "en este sentido podéis y debéis tener un cristianismo africano". Aunque por la terminología empleada puede parecer que se propone únicamente la "adaptación" del mensaje cristiano, dado que la palabra "inculturación" no se había incorporado todavía al lenguaje del magisterio, el sentido de todo el discurso está claramente en la línea de la teología de la inculturación.

13 En un planteamiento de "adaptación" la tradición cristiana es simplemente "traducida" para el contexto cultural africano; mientras que en la perspectiva de la inculturación el cristianismo es "sembrado" para que brote dentro de la propia cultura africana (cf. J. UKPONG, "The Emergence of African Theologies": Theological Studies 45 (1984) 513-516).

14 Cf. C. NyAmiTI, "My Approach to African Theology", 35-53; "Teología de la inculturación: una perspectiva africana": Scripta Theologica 24 (1992) 753-812. 
cristologías de la inculturación de este último tipo, la mayoría de los autores suelen tomar como punto de partida algún aspecto particular de las culturas africanas, muchas veces ligado a determinados grupos étnicos, que consideran especialmente relevante en la comprensión del misterio de Cristo ("thematic aproach"). Con este paradigma como clave de lectura reinterpretan la figura y el mensaje de Jesús tal como lo transmite el NT haciendo uso de los instrumentos lingüísticos locales más adecuados con vistas a darle una expresión que resulte familiar en el contexto africano. C. Nyamiti, en cambio, opta por examinar el misterio de Cristo desde una perspectiva más amplia que denomina "cosmovisión africana" ("African worldview").

\subsection{Cristologías de la liberación}

En el contexto de pobreza deshumanizante del continente africano al que quieren responder las cristologías africanas de la liberación, el interlocutor son sus víctimas, y el retorno al Jesús histórico se presenta como principio hermenéutico para una praxis transformadora. Se busca en la praxis de Jesús el referente vital de una praxis liberadora. El modelo de la liberación no cuestiona la necesidad de recurrir a la crítica histórica para dotar a la fe cristológica de un sólido fundamento, ni discute los dogmas cristológicos de la Iglesia. Todó eso lo asume. Sin embargo, considera que la fe de la Iglesia no consiste en primer lugar en el asentimiento a la verdad de determinadas fórmulas, sino más bien en el seguimiento de Jesús, para acceder desde ahí a su confesión como el Cristo.

En el modelo de la liberación la persona de Jesús y su praxis histórica resultan paradigmáticas. Dando el primado a la ortopraxis, en un contexto concreto de opresión, la actividad de Jesús (curaciones, exorcismos, comensalía) se convierte en el medio de la acción liberadora de Dios en la historia y en una interpelación constante. Tal cristología, aun confesando siempre la identidad personal de Jesús como Hijo de Dios, tiene que ser forzosamente ascendente.

Algún autor ha calificado el planteamiento teológico de L. Magesa de mixto o "combinado" dentro de las cristologías africanas de la liberación"15.

15 Cf. J. UKPONG, "The Emergence of African Theologies", 526-536. Dentro de las cristologías africanas de la liberación se distinguen dos modelos principales: el sudafricano y el latinoamericano. El primero hunde sus raices en la "teología negra" norteamericana y surge como reacción a la política racial del apartheid. El segundo es el modelo más extendido en el 
A diferencia de otros representantes de esta escuela, expresamente influidos por los análisis de la situación sociopolítica propios de la "teología negra" o de la teología latinoamericana de la liberación, Magesa se sirve de elementos originales de carácter local para analizar el contexto africano a la luz del mensaje liberador de Cristo. Trata de fundar así una cristología de la liberación auténticamente africana, que encuentre su propio camino, sin tener que importarlo de fuera. Un proyecto que, por otra parte, tampoco renuncia a incorporar las conquistas de las otras corrientes liberacionistas africanas.

En concreto, detrás de la teología de Magesa no es difícil descubrir la ética social de la Ujamaa ${ }^{16}$. Se trata del socialismo africano de inspiración cristiana, propugnado por J. Nyerere, que pretendía reflejar los modos de vida tradicionales de la población tanzana y, al mismo tiempo, llevar a cabo la progresiva liberación del país del sistema colonial clasista ${ }^{17}$. Una ética social basada en la dignidad de la persona humana, en los valores de la igualdad, la democracia y la autosuficiencia (self reliance), que concibe al ser humano, como íntimamente vinculado a su comunidad, desde la familia hasta el conjunto de la sociedad. Por consiguiente, un modelo social contrario a cualquier forma de discriminación racial, tribal o religiosa ${ }^{18}$. Como se verá a lo largo de la exposición, muchos aspectos de esta filosofía origi-

África subsahariana A estas corrientes hay que sumar la emergente teología feminista africana.

16 Cf. L. Magesa, Ujamaa Socialism in Tanzania, Diss. St. Paul University, Ottawa 1985 (tesis doctoral en filosofía). En la lengua kiswahili significa literalmente "el ser familiar". Expresa a la vez las ideas de fraternidad y participación. El término "solidaridad" puede traducir bien su significado (cf. F. Mushoвozi, La solidarietà in Tanżania alla luce di "Sollicitudo rei socialis" di Giovanni Paolo II. Un studio applicativo dell'insegnamento sociale della Chiesa, Ex. Diss. PUU, Roma 2002, 23-30).

17 "For a people who have been slaves or have been oppressed, exploited and humiliated by colonialism or capitalism 'development' means 'liberation'. Any action that gives them control of their own affairs is an action for development, even if it does not offer them better health or more bread. Any action that reduces their say in determining their own affairs or running their own lives is not development and retards them even if the action brings them a little better health and little more bread. To us development means both elimination for oppression, exploitation and humiliation, and the promotion for our independence and human dignity" (The TANU Guidelines, n.28 citado por F. MuSHOBOZI, La solidarietà in Tanzania, 35 nota 165$)$.

18 Cf. J. NYERERE, Ujamaa, Dar es Salaam 1969, 36-41; Ujamaa: Essays on Socialism, Dar es Salaam 1980, 3-4 (citados por F. MushobozI, La solidarietà in Tanzania, 24). En el campo teológico se debe a C. Lymo la propuesta del modelo de la Ujamaa (cf. C. Lymo, "Quest for Relevant African Theology: Towards an Ujamaa Theology": African Ecclesial Review 18 (1976) 134-144). 
nal y propiamente africana, se pueden reconocer en la cristología liberadora de este teólogo tanzano.

\section{Relectura de los títulos confesionales en las cristologías africanas actuales}

En la primera predicación sobre Jesús la Iglesia apostólica se sirvió de lo que suelen llamarse "títulos" para interpretar el significado de su persona y de su obra. El NT designa a Jesús con más de 50 títulos diferentes. Todos fueron tomados del propio ambiente cultural y religioso en el que nace el cristianismo. Los más frecuentes tienen un significado originalmente veterotestamentario y algunos también extrabíblico (Señor, Verbo, Hijo de Dios). Y en su sentido cristológico un mismo título presenta una pluralidad de matices según los autores, incluso en textos de un mismo autor, atendiendo al sitz im leben de las fuentes. También entre los métodos bíblicos contemporáneos utilizados en el estudio de las cristologías del NT se ha demostrado muy fructífero, no obstante sus límites, el modelo de los títulos cristológicos aplicados a Jesús.

"Y él les preguntaba: Y vosotros, ¿quién decís que soy yo?" (Mc 8,29; cf. Mt 16,15; Lc 9,20). Los tres sinópticos responden por boca de Pedro recurriendo al mismo título mesiánico, pero con expresiones diversas: el Cristo (Mc 8,30), el Cristo, el hijo de Dios vivo (Mt 16,16), el Cristo de Dios (Lc 9,21). La misma pregunta de Jesús en Cesarea de Filipo resuena de nuevo para nuestro tiempo y para cada uno de nosotros personalmente. A partir de las cristologías africanas se descubren nuevas claves de lectura de los títulos cristológicos confesionales. Entendemos por "títulos confesionales" únicamente aquellas denominaciones de Jesús incorporadas al Credo y que se sitúan en el centro de la cristología dogmática (Señor, Mesías, Hijo de Dios) ${ }^{19}$. Con mucha mayor amplitud y en el ámbito de la cristología latinoamericana un magnífico estudio sistemático en este sentido es el realizado por J. Sobrino. Resulta sumamente iluminador su planteamiento hermenéutico en el proceso de aplicación de los títulos a Jesús ${ }^{20}$. Lo trasladamos al contexto africano en los puntos que siguen.

19 Cf. X. PIKAZA, Este es el hombre, Salamanca 1997, 213. Este autor los distingue de los títulos referenciales. Según él, estos últimos no se emplean directamente para expresar la fe en Jesucristo, sino para situar su figura en el contexto de la historia humana o de la acción escatológica de Dios (Hijo del hombre, Siervo de Dios, Logos). Además de estos dos grupos habla también de títulos soteriológicos.

20 Cf. J. Sobrino, La fe en Jesucristo, Madrid 1999, 176-179. En un primer "momento lógico y cronológico" Jesús es comprendido a partir de los títulos que se le aplican. Pero es 


\subsection{Señor: el líder y "Maestro de iniciación"}

La imagen de Cristo como líder ${ }^{21}$, como el soberano que viene y en cuya presencia se está al seguro, es un símbolo propuesto ya inicialmente por las iglesias misioneras en un primer intento por "adaptar" la figura de Jesús al mundo africano. Sin embargo, no es una imagen del todo feliz porque los "jefes" eran entonces, y seguramente siguen siendo hoy, personas por lo general bastante lejanas e inaccesibles a sus propios súbditos.

H. Sawyerr no lo considera un título aplicable a Jesús por varios motivos. En primer lugar, porque los líderes (chiefs) africanos actuales han perdido hoy el prestigio y el influjo positivo que tuvieron en otros tiempos. También porque, en todo caso, el ejercicio del liderazgo no está nunca libre de cuestionamientos y críticas. Y finalmente, porque los jefes, a menudo, suelen vivir en residencias protegidas, apartados de los lugares donde discurre la vida de la gente común 22 .

El objetivo principal de la cristología del keniata J. Mbiti es intentar descubrir los elementos que pueden interesar de modo particular a la conciencia africana y confrontar la enseñanza neotestamentaria sobre Jesús con sus propias tradiciones. Mbiti repasa los paralelismos y las divergencias entre el Cristo bíblico y la cultura africana haciendo uso de las ciencias auxiliares de la teología (p.e. la antropología cultural), además de la filosofía. Y de forma rigurosa va descubriendo también semejanzas en las diferencias y diferencias en las semejanzas. Con este método comparativo analiza varios títulos cristológicos presentes entre algunas tribus africanas: "Hijo de Dios", "Siervo de Dios", "Redentor", "Señor", etc. Pero subraya igualmente los elementos cristológicos importantes, sin paralelo en las tradiciones africanas.

Según Mbiti, la imagen del "Christus Victor" ("Señor de los milagros" y "Señor resucitado") es particularmente relevante porque representa su poder sobre el dominio del mal (espíritus, magia, enfermedades, muerte) como garantía de inmortalidad ${ }^{23}$. Algún autor, en cambio, ha tachado inclu-

necesario que después, en un "momento epistemológico", los títulos sean releídos y explicados a partir de Jesús.

${ }^{21}$ Una visión de conjunto del uso de este título se puede ver en F. KABASÉLÉ, "Christ as Chief" en Faces of Jesus in Africa, 103-115.

22 Cf. H. SAWYERR, Creative Evangelism: Toward a New Christian Encounter with Africa, London 1968, 72-74.

23 Cf. J. MBITI, "Some African Concepts of Cristology" en G.F. VICEDOM, ed., Christ and the Younger Churches, London 1972, 51. 
so de "peligrosa" esta imagen de Cristo porque representaría una teología de la gloria a la que falta la teología de la cruz ${ }^{24}$.

Por su parte K.A. Dickson ha desmentido tales sospechas. Este autor comienza criticando el carácter negativo y pesimista de ciertas cristologías occidentales que tienden a sobredimensionar el significado de la cruz, convirtiéndola en "un desastre, un lamentable preludio de la Pascua". Según él, en el complejo estilo de vida de las sociedades occidentales la muerte ha dejado de ser un acontecimiento público que implica a toda la comunidad, para convertirse en algo privado e inevitable que conviene olvidar cuanto antes. En cambio, las sociedades africanas tradicionales entienden la muerte como producto del mal; y ese mal tiene siempre un agente. La vida no termina con la muerte, ni terminan con ella los vínculos con los vivos. Es la ocasión para buscar la vida. Por eso, dentro de los ritos funerarios se suelen incluir también ciertos rituales festivos y de comensalía. Todo ello para significar que la vida sigue. La muerte tiene una amplia repercusión social. En ningún caso es un evento que afecta sola y exclusivamente a la familia directa del difunto.

A la luz del mensaje neotestamentario, Dickson elabora una teología de la cruz ${ }^{25}$ que responde a esa comprensión africana de la muerte. La cruz constituye "la base de la esperanza cristiana": simboliza la degradación y la maldad humanas, pero también el "triunfo" sobre ellas. La cruz no es signo de vergüenza o humillación, sino el símbolo de la perfección, sin que esta interpretación subestime el carácter sacrificial ni las consecuencias soteriológicas de la muerte de Jesús. Para él, el sacrificio y la salvación, más que la causa, son consecuencias derivadas de la "victoria" de la cruz.

Jesús como "Guía" ("Head") y "Maestro de Iniciación" es el tema sobre el que desarrolla su cristología el obispo de Burkina Faso A.T. Sanon ${ }^{26}$. Como en todas las demás culturas, este autor observa que también los ritos de iniciación acompañan las diversas etapas de la vida (life crisis) en las sociedades africanas: el nacimiento, el paso de la adolescencia a la edad adulta, el matrimonio y la muerte. Estos procesos iniciáticos reproducen la misma estructura de los "ritos de paso" con sus tiempos característicos (liminaridad), siguiendo la secuencia simbólica de muerte y resurrección.

24 "In other words, the Chief analogy denotes authority and power derived from other ways than the way of suffering and humanity (Lk 24:46ff)" (J.S. POBEE, Toward an African Theology, Nashville 1979, 97).

25 Cf. K.A. Dickson, Theology in Africa, New York 1984, 185-199.

26 Cf. A.T. SANON, "Jesus, Master of Initiation" en Faces of Jesus in Africa, 85-102. 
Tras esa descripción antropológica, Sanon aplica los esquemas de la iniciación africana a la comprensión del misterio de Cristo. De acuerdo con la enseñanza del NT (sobre todo en las cartas a los Filipenses, a los Hebreos y en los evangelios sinópticos), descubre en la vida de Jesús un proceso por etapas hacia una meta (cf. Hb 2,10; 5,9; 7,28). Acontecimientos como el nacimiento, el bautismo o la muerte muestran a Jesús como un hombre perfecto que ha afrontado con éxito los "ritos de paso". Señala cómo Jesús fue iniciado según los ritos de la tradición judía (nacimiento, circuncisión, imposición del nombre, presentación en el templo) para pasar a pertenecer a su familia y a su comunidad. En esta línea identifica varios temas y elementos iniciáticos relacionados con la vida de Jesús: el "secreto mesiánico", la predicación en parábolas, los signos milagrosos, etc. Del mismo modo, Sanon interpreta el episodio del lavatorio de los pies durante la última cena como un gesto iniciático. Jesús, el maestro, inicia a sus discípulos en el camino que deberán recorrer: les instruye y les prepara para seguir sus pasos (amor, perdón). Pero el momento culminante del proceso de iniciación seguido por Cristo hay que situarlo obviamente en la Pascua. Tras su muerte en la cruz (= "árbol de la vida"), con su Resurrección, se produce una real transformación de su persona. Cristo alcanza una nueva condición. Supone el tránsito a una nueva vida, más allá de la muerte.

También la iglesia postpascual es una comunidad que se va formando después de una primera iniciación dura y que debe continuar "en el camino de iniciación con la mirada puesta decididamente en su Maestro que la ha establecido". De esta forma, Jesús asume la función de guía de la iniciación. El es el Maestro porque el Verbo mismo fue a su vez iniciado por un tiempo en la religión judía por medio de su encarnación. Al respecto escribe Sanon:

Jesús es nuestro perfecto maestro de iniciación, nos ha mostrado los valores más altos en forma de símbolos. Estos valores son: el amor a Dios y al prójimo, la adoración, la súplica... Estos valores vitales absolutos los comprendemos a través de símbolos familiares: el leño de la cruz, el agua del bautismo, el pan y el comer en familia... Enraizados en estos símbolos entramos en el mundo de los valores de Cristo...27.

El proceso de iniciación seguido por Jesús le ha convertido en nuestro perfecto Maestro de iniciación. Le ha convertido en "fuente de eterna salvación para los que le obedecen" (Hb 5,9). Participar de su iniciación signi-

\footnotetext{
27 Id., Enraciner l'évangile. Initiations africaines et pédagogie de la foi, Paris 1982, 118119.
} 
fica seguir las etapas de su camino hacia la cruz movidos por el amor. Mediante el bautismo somos incorporados a Cristo, participando de su misma muerte y resurrección.

\subsection{Mesías: el Sanador y Liberador}

Hay dos situaciones humanas fundamentales que sirven de referencia para elaborar la noción bíblica de salvación: la enfermedad y la esclavitud. Frente a la enfermedad, signo precursor de la muerte, salvarse significa obtener la salud; frente a la esclavitud, salvarse significa conseguir la libertad.

La experiencia de la propia curación por la fe suele ser la razón más común del ingreso en las iglesias independientes de tipo profético. Son ellas las que dan mayor relieve a este modelo de Cristo como nganga, protector contra las fuerzas malignas 28 . Su ministerio sanador y liberador ocupa el lugar del brujo o curandero (medicine man), desplazando a quienes en la medicina tradicional africana realizan esa función, imponiendo las manos y haciendo exorcismos rituales de los malos espíritus.

Lo que ha cargado de tensión esta imagen de Cristo, es que con frecuencia el nganga de las tribus africanas haya sido considerado por los misioneros y predicadores, tanto católicos como protestantes, como el adversario de Cristo por antonomasia. De ahí la resistencia de las iglesias misioneras a emplear este título aplicado a Cristo. Por un lado, es verdad que comporta el riesgo de que el hechicero de la tribu o los propios ministros cristianos sean identificados idolátricamente con Cristo; pero por otro, no hay que olvidar tres datos fundamentales: que los relatos taumatúrgicos constituyen la mayor parte del material sinóptico sobre la actividad de Jesús, que Jesús mismo se muestra muy tolerante con los "brujos" a quienes los discípulos intentan impedir que curen (cf. Mc 9,38-40 par) y que "Cristomédico" es uno de los títulos predilectos de la cristología patrística.

En cualquier caso, lo cierto es que el "paradigma terapéutico" está muy presente también en las cristologías sistemáticas africanas ${ }^{29}$. Entre los auto-

\footnotetext{
28 Es un término procedente de las lenguas bantúes que puede significar tanto "curandero" como "sacerdote". Cf. J. PARRATt, Reinventing Christianity. African Theology Today, New Jersey 1995, 84-85. Un estudio monográfico sobre este título se puede ver en C. KoLIÉ, "Jesus as Healer?" en Faces of Jesus in Africa, 128-150.

29 Cf. J.N.K. Mugambi, "Christological Paradigms in African Christianity" en Jesus in African Christianity, 156.
} 
res ha sido probablemente A. Shorter el que ha desarrollado más esta perspectiva $^{30}$.

Según los sumarios que se presentan al comienzo de los evangelios, las curaciones constituyen un elemento central de la actividad de Jesús: Jesús "curaba a los enfermos y expulsaba demonios". Para sentar las bases de su cristología, Shorter pone en relación las curaciones milagrosas realizadas por Jesús y las técnicas de los curanderos tradicionales africanos. Descubre entre ellas significativas semejanzas. Por un lado, señala que en ambos casos se trata de prácticas de sanación de la totalidad de la persona: no sólo a nivel físico, sino también psíquico, moral, social y espiritual. Igualmente otro rasgo común es que comparten la misma precomprensión de la enfermedad como castigo de un pecado personal. Tanto en la cultura mediterránea del tiempo de Jesús como en el mundo africano tradicional, la hechicería y las posesiones son creencias mayoritariamente admitidas socialmente.

Sin embargo, por otro lado, Jesús relativiza siempre sus poderes y previene a sus seguidores frente a interpretaciones de carácter mágico. En el mensaje de Jesús, más allá de las curaciones de enfermedades concretas, se apunta hacia una superación total y definitiva de la enfermedad. Y con su propia muerte en la cruz revela el poder salvífico del sufrimiento. Por eso Shorter denomina a Jesús "Sanador herido" y "Víctima". Esta condición no desaparece en su estado glorioso: "sigue mostrando sus heridas al Padre y por medio de ellas sigue curando a la humanidad".

Los sacramentos, y en especial la eucaristía, que renueva el misterio de la cruz y la resurrección de Jesús, son la obra del Espíritu, a quien Shorter se refiere como "medicina de la vida" porque continúa en el mundo la misión salvífica de Cristo.

Finalmente, Shorter describe algunas de las implicaciones antropológicas, psicológicas, ecológicas y sociales que se deducen de su cristología. Y la propone como un estímulo beneficioso para todos, incluso más allá del contexto africano ${ }^{31}$.

Por otra parte, la imagen de la libertad nos presenta la salvación como liberación. El pueblo de Israel vive la gesta del éxodo como un símbolo de la liberación de la esclavitud de Egipto. La muerte y resurrección de Jesús

30 Cf. A. SHORTER, "Folk Christianity and Functional Christology": African Ecclesial Review 24 (1982) 133-137; Id., Jesus and the Witchdoctor. An approach to healing and wholeness, London - New York 1985; Id., "Christian healing and traditional medícine in Africa": Kerygma 20 (1986) 51-58.

31 "[This approach to healing] can produce a corrective for western scientific medicine which had become so effective at the phisycal level that it encourages an unfounded belief in its infallibility and leads to extremes of dispair in terminal cases" (Id., "Christian healing and traditional medicine in Africa", 58). 
se va a interpretar en el NT en esta misma clave pascual. Cristo es el Mesías Liberador. En este sentido Él es el Salvador.

Como reacción a siglos de dominación y explotación, la idea de un "mesías negro" que liberará a los africanos de la esclavitud y la opresión es un tema latente a lo largo de la historia de los movimientos religiosos africanos, incluso ya antes de la última incursión misionera del s. XIX. Todavía hoy alguna de las iglesias independientes ve encarnado en su fundador ese rol mesiánico ${ }^{32}$.

"Cristo liberador" es el título privilegiado por las diversas cristologías de la liberación africanas. En torno a esa figura han elaborado su discurso de contestación racial y política frente al apartheid los representantes de la teología negra sudafricana. Pero probablemente nadie lo ha reivindicado con más fuerza que el camerunés J.-M. Ela en su análisis de las situaciones concretas de pobreza y de marginación, a partir de las cuales presenta el evangelio como fuerza de liberación:

En un contexto en el que se enfrentan los pueblos dominantes y dominados, la tarea de la Iglesia consiste en revelar a los hombres el rostro de Jesús liberador, a partir de una práctica de la fe y una relectura del Evangelio en la que se concreta la solidaridad de la Iglesia con los pobres y oprimidos ${ }^{33}$.

El pastor metodista $Z$. Nthamburi ofrece un estudio específicamente cristológico desde la perspectiva de la liberación ${ }^{34}$. Después de recordar cómo con la expansión de la Iglesia entre los gentiles el título "Mesías" va siendo reemplazado por su equivalente griego "Cristo" hasta quedar incorporado al nombre de Jesús, este autor apuesta decididamente por una cristología ascendente ("anthropocentric christology") para una mejor comprensión de la obra salvífica de Cristo en el contexto africano. Inspirándose en algunos teólogos latinoamericanos, considera igualmente que su punto de partida no puede ser otro que la praxis de Jesús de Nazaret, que incluye

32 Por ejemplo en la Iglesia de los apóstoles de Masowe: "Just as Jesus is belived to be the father of salvation history for the Jews and for the white races... so Johane has now become the father of salvation history for African peoples... Johane is, indeed... the 'last saviour of the last church' for the peoples of Africa [...] The Apostles have adopted the hebrew word 'messiah' to refer to their founder as their saviour" (C.M. Dillon-Malone, The Korsten Basketmakers. The Study of the Masowe Apostles, an Indigenuos African Religious Movement, Lusaka 1978, 60-61).

33 J.-M. ElA, El grito del hombre africano. Cuestiones dirigidas a los cristianos y a las Iglesias de Africa, Estella 1998, 78-79.

34 Cf. Z. NTHAMBURI, "Christ as seen by an African: a Christological Quest" en Jesus in African Christianity, 54-58. 
su persona, su ministerio y su muerte y resurrección. Pues de hecho fue esa praxis la que llevó a sus discípulos a confesarle como el verdadero Mesías de Dios (cf. Mt 15,15 par).

La revelación divina es necesariamente histórica. Dios se automanifiesta para darse a conocer mediante un proceso intrahistórico que culmina en la persona de Jesús, confesado como el Cristo. Según la economía de la encarnación, la Palabra de Dios se hace carne para que el ser humano pueda ser transformado y participar de la gloria de Dios. La encarnación supone la superación de las barreras entre lo divino y lo humano, lo sagrado y lo profano, lo religioso y lo secular. La única dicotomía que se mantiene es la que distingue lo verdadero de lo falso, la justicia de la injusticia, la paz de la violencia.

En la situación africana, Cristo se identifica necesariamente con los sufrimientos, la debilidad y el dolor de sus gentes en medio del hambre, la opresión y la falta de dignidad. En la praxis de Jesús no hay espacio para la neutralidad ni las componendas ante el mal y las injusticias. En estos casos los silencios son cómplices. "Si Cristo sólo tiene incidencia en la vida ordinaria en la esfera de la espiritualidad y su praxis no tiene relación con todos los demás ámbitos de la existencia (sociales, políticos, económicos), entonces no será relevante para África"35. Sólo como liberador, Cristo se convierte en "nuestro mediador, salvador, redentor y esperanza".

Comienza a ser cada vez más viva en la conciencia africana la convicción de que Jesús no ha venido sólo para curar a los enfermos y redimir a "los pecadores", sino también para salvar a "aquellos contra quienes se peca"; no sólo a "redimir a los pobres", sino a "liberar a los empobrecidos". Sin que ello suponga en ningún caso dar lugar a una polarización en torno al significado de la persona y la obra de Jesús que contraponga unilateralmente liberación presente y salvación futura. M. McVeigh ayuda a superar el dilema con la imagen de tres riachuelos que desembocan en el mismo lago: el primero proviene del cristianismo misionero que entiende la redención como liberación del pecado; el segundo de la teología de la liberación que insiste en la redención como liberación de situaciones de opresión política, social y económica; el tercero de las tradiciones africanas que interpretan la redención como liberación de fuerzas malignas objetivas (desgracias, tragedias vitales) ${ }^{36}$. Esta concepción coincide perfectamente con la

\footnotetext{
35 Ibid., 58.

36 Cf. M.J. MCVEIGH, "Sources for an African Christian Theology": Presence 3 (1972) 2-4.
} 
obra de Jesús (cf. Mt 11,2-6 par; Lc 4,16-21) y la misión que confía a sus seguidores (cf. Mt 10,7-8 par; Jn 20,21-23).

\subsection{Hijo de Dios: el Antecesor o Antepasado original}

Para poner de relieve la filiación divina de Jesús, el modelo de la teología de los antepasados es, sin duda, el más seguido y el mejor estudiado en las cristologías sistemáticas africanas ${ }^{37}$. En el NT la ascendencia de Jesús es presentada con diversos títulos (Hijo de Abraham, Hijo de David, Hijo del hombre, Hijo de Dios). Y atraídos por el origen de Jesús, varios autores muestran gran interés por las genealogías (Mt 1,1-17; Lc 3,23-38) de los evangelios ${ }^{38}$.

En su cristología funcional en diálogo con la mentalidad del pueblo Akan, el teólogo ghanés J.S. Pobee comienza sus reflexiones a partir de la confesión de Cristo como "verdadero Dios y verdadero hombre" (DH 125). Según él, Cristo es el "gran antepasado" (Nana en la lengua Akan). Como tal tiene el poder y la autoridad para juzgar, recompensar y castigar. Pero como hombre-Dios es superior a todos los antepasados y a todos los espíritus, y esto tiene importantes consecuencias prácticas ${ }^{39}$.

Siguiendo este mismo enfoque temático, a partir de la cultura de la tribu Shona, A. Moyo presenta a Jesús como espíritu intermediario entre Dios y la humanidad. Lo denomina "Supremo espíritu universal de los antepasados" a través del cual todos los demás espíritus tienen acceso a Dios ${ }^{40}$. En la religión tradicional del pueblo Shona, Dios es descrito como Mudzimu Mukuru ("Gran Espíritu Ancestral") o como Mudzimu Unoyera (“el Santo Espíritu de los antepasados"). Dado que Jesús es descendiente

37 Una amplia bibliografía se puede consultar en F. KABASÉLÉ, "Le Christ comme Ancêtre et Aîne" en Chemins de la christologie africaine, 127-141 y C. NYAMITI, "African Christologies Today" en Jesus in African Christianity, 17-39. Los dos artículos están reproducidos en R. SCHREITER, ed., Faces of Jesus in Africa, 116-127 y 3-23.

38 Sobre los "paradigmas genealógicos", cf. J.N.K. MUGAMBI, "Christological Paradigms in African Christianity" en Jesus in African Christianity, 140.

39 "To say Jesus is Nana is to let his standards reign supreme in personal orientation, in the structures of society, in the economic processes, and in political forces. It means in practical terms personal and social justice and re-creation" (J.S. POBEE, Toward an African Theo$\log y, 98)$.

40 A.M. Moyo, "The Quest for African Christian Theology and the Problem of the Relationship between Faith and Culture. The Hermeneutical Perspective": African Theological Journal 12 (1983) 97. J. Mutiso-Mbinda subraya de modo semejante el carácter de intermediario intercesor de Cristo, denominándolo "Ancestor par excellence" (J. MUTISO-MBINDA, Anthropology and the paschal mystery (Spearhead 59), Eldoret 1979, 52). 
directo de Dios, se convierte en nuestro Antecesor con poderes de intercesor. $\mathrm{Su}$ ascendencia judía pasa a un segundo plano desde el momento en que se ha convertido para nosotros en Antecesor "Celeste" (Nyadenga). Moyo concluye afirmando que Jesús, como el espíritu celeste de Dios y antecesor universal, representa la nueva fuente que une a todo el linaje humano.

Sobre la base de la compresión ritual y la actitud ante la vida y la muerte de la tribu Ewe-Mina (Togo), la cristología de E.J. Penoukou tiene una perspectiva espiritual e histórica más amplia que la de los autores anteriores ("cosmotheandric vision")41. Según su concepción, la vida y la muerte aparecen mutuamente implicadas: la vida es vista más allá de la muerte y la muerte entendida como un "paso" necesario hacia la vida. Concibe la realidad global como un organismo vivo en proceso de perpetua regeneración a través de tres fases sucesivas: nacimiento, muerte y renacimiento. Son los momentos de realización de lo que él llama el "estar-ahí-con" los otros (Dios, los espíritus, el cosmos, los seres humanos). Se puede descubrir así cierto proceso ontológico dentro de una relación cosmoteándrica entre el Ser Supremo y el universo socio-cósmico.

A la luz de esta compleja cosmovisión, Penoukou reflexiona sobre el acontecimiento-Cristo de un modo que recuerda la "cristogénesis" de P. Teilhard de Chardin. Según él, se trata de "un paso", de una etapa de realización del proyecto de ser. Habiendo tenido una existencia previa ${ }^{42}$ y habiéndose vaciado a sí mismo (cf. Flp 2,7) para hacerse hombre, Cristo padeció la muerte como paso necesario para un nuevo tipo de vida. Cristo es el mediador ("organic medium") entre Dios Padre y toda la creación ${ }^{43}$. Puesto que todo ha sido creado "por medio de Él y para Él" (Col 1,16), la encarnación es la suprema expresión de la relación cosmoteándrica. Por su encarnación, muerte y resurrección, Cristo se convierte en el centro de la historia y del universo. De este modo es el Joto-Antepasado, el Antepasado que es fuente de vida y energía vital.

Para el congoleño B. Bujo a través de los ritos se actualiza constantemente la sabiduría de los antepasados para que se convierta en modelo de

41 Cf. E.J. Penoukou, "Réalité africaine et salut en Jésus-Christ": Spiritus 23 (1982) 374392; Id., "Christology in the Village" en Faces of Jesus in Africa, 24-51.

42 La creencia cristiana en la "preexistencia" de Cristo, en cambio, no tiene paralelo en la religión Akan, estudiada por J.S. Pobee.

43 En la Iglesia independiente de Isaiah Shembe, entre los Zulú (Sudáfrica), precisamente para salvar la igualdad con Dios creador, no se aplica a Cristo el título de "Hijo", porque se considera que un hijo es siempre inferior a su padre. 
conducta de sus descendientes. Esos rituales son una especie de "soteriología narrativa conmemorativa" que asegura la unidad del pasado, el presente y el futuro de la comunidad, incluidos los muertos ${ }^{44}$.

Desde esa perspectiva interpreta la última cena de Jesús con sus discípulos como la última hora de un padre de familia moribundo, que reúne a sus hijos junto al lecho de muerte para hacerles partícipes de su última voluntad. El testamento de Jesús es servicio y amor mutuo: "Sólo quien se atiene a este mandamiento tiene la vida y puede trasmitir a los demás la fuerza vital" (cf. Jn 13,17) 45 .

Jesús no es sólo un antepasado, ni siquiera el primero de los antepasados ("antepasado original") entre tantos otros. Hay que designarlo más bien con el título de "Proto-antepasado".

Con ello se quiere significar que Jesucristo no sólo realiza perfectamente el ideal de vida de los antepasados negro-africanos, temerosos de Dios, sino que transciende ese ideal infinitamente y lo lleva a la perfección. Quiere decir que no ha habido ni es posible imaginar otro antepasado que haya logrado una realización y una perfección semejante [...]

Jesucristo es la imagen originaria de todas las virtudes ancestrales y de la salvación que tanto anhelaban nuestros pređecesores. Más aún, Jesucristo es el protoantepasado, la fuerza vital primordial, que está en el comienzo de toda posible "unión vital", de un modo absolutamente insuperable. En la resurrección Jesús ha sido acogido de una vez para siempre en la gloria de Dios: el es la vida -no sólo tiene la vida-y llama a la vida (cf. Jn 11,25)[...]

Tras lo dicho, no se trata de atribuirle el título de proto-antepasado superficialmente o por capricho de moda, como si no fuera más que una etiqueta, sin correspondencia alguna con la realidad. Mi propuesta está relacionada con la encarnación del Verbo... En realidad, Jesucristo, se ha identificado con la humanidad como constituyendo su exégesis. Desde ese momento ha hecho propias todas las justas aspiraciones y toda la historia de nuestros antepasados, de modo que esas se han convertido en lugar del encuentro con el Dios de la salvación. Ante todo es Jesucristo mismo el único lugar privilegiado en el que hoy los antepasados pueden ser perfectamente comprendidos... (cf. Hb 1,1-2)... Los antepasados negro-africanos, son sólo imágenes derivadas del Proto-antepasado, de Jesucristo. Él es el salvador, y el recuerdo de su pasión, muerte y resurrección debe ser continuamente narrado de generación en generación... ${ }^{46}$.

44 Cf. B. BuJo, "Pour une éthique africano-christocentrique": Bulletin de la théologie africaine 3 (1981) 41-52.

45 Id., African Theology in Its Social Context, Nairobi 1992, 79-80.

46 Ibid., 80-83. 
Según Bujo, para el negro africano este título es mucho más significativo que el de Logos o Kyrios que pertenecen a otras culturas bien determinadas y puede incluir e integrar perfectamente a los otros títulos cristológi$\cos$ africanos ${ }^{47}$. Y por otra parte, Cristo como "Proto-antepasado" es el fundamento de una ética narrativa que lo presenta como modelo de vida y de conducta humana. Esta ética cristocéntrica confirma muchos elementos propios de la cultura africana (hospitalidad, sentido de familia, atención a los padres) al tiempo que corrige y completa las costumbres africanas tradicionales y modernas.

Hasta la fecha el estudio sistemático más completo sobre Cristo como "Antepasado" es el realizado por C. Nyamiti en 1984. En el siguiente apartado trazamos las líneas fundamentales de su cristología.

\section{El proyecto cristológico de C. Nyamiti}

\subsection{Cristo, el "Hermano Antepasado"}

En muchas sociedades africanas la personalidad, más que en términos ontológicos, se concibe en términos vitales, en el sentido de que lo que constituye la personalidad del individuo se entiende, sobre todo, como plenitud de vida o madurez vital. Esto implica fundamentalmente fecundidad (a todos los niveles, no sólo biológica), sabiduría práctica (que supone el conocimiento de las tradiciones ancestrales), sentido de lo sagrado (el Ser Supremo y sus mediaciones), plena apertura hacia la comunidad humana (tanto de los vivos como de los difuntos) y hacia la naturaleza, y por último, la conciencia de la propia libertad (entendida no sólo como emancipación, sino también como reconocimiento).

Sobre la base de estos elementos vitales tradicionales, Nyamiti elabora una teología africana de la encarnación ${ }^{48}$. La idea de encarnación representa lo que para la cultura africana significa la plenitud de la propia identidad personal: llegar a ser verdaderamente humano, y por tanto, también auténticamente africano. En este sentido el Logos encarnado es el "hombre negro por excelencia" 49 . Por consiguiente, no existe una noción genuina de

47 Se refiere en concreto a los títulos "Maestro de Iniciación" y "Sanador" (cf. Ibid., 85).

48. Cf. "The Incarnation viewed from the African understanding of person", 3-27.

49 Nyamiti emplea la expresión "Cristo es negro" para indicar que para la antropología cristiana, con independencia del color de la piel, Cristo entra en la definición del hombre. La 
lo que es el negro africano (negritude) al margen de Cristo. Como un momento de plenitud de la propia identidad personal, en el sentido expuesto, el misterio de la encarnación aparece directamente unido al misterio trinitario, a la antropología y la eclesiología 50 .

Nyamiti pone de relieve como Jesús siguió los ritos de paso tradicionales para incorporarse como adulto dentro de su comunidad51. De este modo la encarnación, entendida como la adquisición de la plena personalidad de Cristo, supone también su iniciación en los valores y las tradiciones sociales y religiosas de su pueblo.

Esta aproximación vital al misterio de Cristo es, según Nyamiti, un paso necesario para comprender el misterio de la encarnación en contexto africano y lleva también a una comprensión más personalista de los otros misterios con los que está estrechamente vinculado. Desde el punto de vista cristiano la identidad africana se realiza en la autoidentificación con Cristo y por eso la tarea de la espiritualidad africana consiste en orientar a los creyentes hacia la actualización práctica de tal identidad en la actual situación sociocultural.

Nyamiti basa su modelo cristológico en la comprensión africana de los antepasados $^{52}$. Su punto de partida son las creencias y prácticas presentes en la mayoría de las sociedades tradicionales africanas ${ }^{53}$. Según él, la relación con los antepasados comporta cinco elementos constantes: parentesco, status sagrado, función mediadora, ejemplaridad y comunicación sagrada. La relación de parentesco entre vivos y difuntos, consanguínea o no, con-

Black Theology emplea la misma expresión pero en un sentido diverso con fuertes connotaciones raciales, para subrayar la identificación de Cristo con la causa de los oprimidos.

50 Una constate en toda la obra teológica de Nyamiti es su interés por mostrar el nexus mysteriorum (cf. DH 3016). "If one takes into account the teaching that all the Christian mysteries are organically interconnected (nexus mysteriorum) in such a way that it is possible to gain a deeper understanding of one particular mystery (in itself and in its relevance for us) in the light of others" ("African Christologies Today", 30).

$51 \mathrm{Cf}$. "Christ's ministry in the light of African tribal initiation ritual", 65-87.

52 Son muchas las obras de cristología que siguen este paradigma. Una buena orientación bibliográfica se puede encontrar en "African Christologies Today", 37 notas 12 y 13. Cf. "Ancestor Veneration in Africa" en www.afrikaworld.net/afrel/nyamiti.htm.

53 "There is not uniform system of beliefs and practices of this cult in black Africa. In fact, one finds differences of detail even in the same ethnic group. Moreover, the ancestral veneration which will be described here is not found in each African Traditional Community. Nevertheless the cult belongs to the mayority of the African Peoples. Besides, not with standing the differences refered to above, there are many elements shared in common conceptions on ancestors and their cult among black africans" (C. NYAMITI, "Ancestral Kinship in the Trinity: an African Theology of the Trinity" en AA.VV., Inculturation: working papers on living faith and cultures IX, Rome 1987, 38). 
vierte al antepasado, en muchos casos, en fuente vital para sus parientes terrenos. El antepasado, a través de la muerte, adquiere una condición sagrada que incluye su cercanía con Dios, poderes sagrados y otras cualidades suprahumanas. El antepasado desempeña un rol mediador entre los vivos y los difuntos y, a veces, entre el Ser Supremo y sus parientes terrenos. La memoria del antepasado se convierte para sus descendientes en modelo de comportamiento en la comunidad. Por último, el antepasado mantiene una frecuente comunicación con sus parientes vivos a través de diversas prácticas rituales (plegarias u ofrendas). Nyamiti describe el "antepasado ideal" como:

Un ascendiente directo de otra persona, de quien es el arquetipo, tanto natural como comportamental, y con quien está legitimado a mantener una constante relación sagrada a través de algún tipo de comunicación ${ }^{54}$

Desde esta comprensión de la relación con los antepasados, según Nyamiti, es posible examinar la vida intradivina y descubrir que también hay un parentesco ancestral eterno, inmanente y absolutamente necesario entre las personas divinas: el Padre es el Antecesor del Hijo y el Hijo, a su vez, aparece como Descendiente del Padre. Padre e Hijo viven sus relaciones divinas a través del Espíritu que se comunican mutuamente como ofrenda ancestral. El Espíritu es donado recíproca y gratuitamente como Amor mutuo (don) y Santidad mutua (oblación). Por eso, para Nyamiti, en Dios hay un verdadero ritual doxológico y eucarístico. Este "ritual trinitario" constituye el modelo de referencia de todos los demás. Su fin último es la comunión íntima entre el Padre (Antecesor), el Hijo (Descendiente) y el Espíritu Santo ("pneumatic perichoresis"). Por eso, en Dios los términos "Antecesor" y "Descendiente" son categorías esencialmente doxológicas, eucarísticas, pneumáticas y rituales.

Desde esta perspectiva, por su condición teándrica y su función redentora, Cristo es nuestro "Hermano-Antepasado por excelencia". La ascendencia de Cristo, enraizada en la vida trinitaria, representa la traducción económica de su eterna descendencia de Dios Padre para nuestra salvación. Es su ascendencia redentora como Logos encarnado. La encarnación y el ministerio redentor de Cristo, que culmina en el misterio pascual, son la prolongación terrena de la comunicación trinitaria ancestral a la persona de Jesús y, a través de él, a toda la creación. Cristo nos comunica su filiación

${ }^{54}$ C. Nyamiti, African Tradition and the Christian God (Spearhead 49), Eldoret 1977, 48. 
ancestral mediante el Espíritu Santo, en virtud de la misión salvífica que ha recibido del Padre 55 . A través de Cristo, Dios Padre se convierte también en nuestro Antecesor ${ }^{56}$.

En virtud de esa unidad con su descendencia redimida, la descendencia del Redentor goza de las mismas características que su ascendencia posee en la Trinidad. Y puesto que el Salvador es profeta, rey, sacerdote y mesías escatológico, su descendencia debe ser también profética, real, sacerdotal y escatológica. Nyamiti descubre la función profético-ancestral de Cristo y el significado ancestral de su actividad curativa. Por medio de la actividad redentora de Jesús durante su ministerio terreno y tras su exaltación pascual, la descendencia de Cristo va creciendo gradualmente hasta alcanzar su plenitud en la Parusía.

Como se puede observar la ascendencia de Cristo aparece en la cristología de Nyamiti firmemente fundamentada en el misterio trinitario y en íntima relación con la eclesiología.

Para Nyamiti son dos las razones principales de la importancia de la teología trinitaria para la cristología en general y para la cristología africana en particular. En primer lugar, señala el valor que tiene para descubrir la identidad de la persona de Jesús y su relevancia para nosotros. Cristo es "verdadero Dios y verdadero hombre". No simplemente un hombre, por perfecto que pueda ser. Según las Escrituras, Cristo es el unigénito del Padre, enviado al mundo para realizar nuestra salvación en virtud del poder del Espíritu de Dios. Al margen de este presupuesto trinitario, la verdadera identidad de Jesús resulta irreconociblemente reducida.

En segundo lugar, la teología trinitaria interesa a la cristología por la centralidad del misterio trinitario para la vida cristiana. De acuerdo con la revelación cristiana, el motivo de la autocomunicación divina no es otro que hacernos partícipes de su propia vida divina (cf. 2Pe 1,4), haciéndonos "hijos en el Hijo" mediante el Espíritu. La vida cristiana consiste, por tanto, en vivir como hijos del mismo Padre y verdaderos hermanos del Hijo en el Espíritu. Sin esta base, según Nyamiti, toda teología resulta radicalmente superficial. Prescindiendo de la Trinidad, el misterio de Cristo mismo pierde toda razón de ser, pues Él es el revelador del Padre y el comunicador del Espíritu. Nyamiti considera particularmente importante subrayar esta cues-

55 Cf. Christ as our Ancestor. Christology from an African Perspective, 27, 42-43 y 49-50.

56 Nyamiti llama a Dios Padre "Parent-ancestor", mientras que Cristo es "Brother-ancestor" (Ibid., 23). 
tión pues entiende que uno de los puntos débiles de muchas cristologías africanas es que adolecen de esta perspectiva trinitaria ${ }^{57}$.

Por otra parte, la teología de la ascendencia del Hijo de Dios debe completarse mostrando sus consecuencias eclesiológicas. "La Iglesia es la extensión de la ascendencia de Cristo en las comunidades humanas"58. De hecho, resulta incompleta una cristología de la Cabeza sin su Cuerpo, la Iglesia ${ }^{59}$. Por consiguiente, aunque pueda ser legítima una cristología de Cristo solo, será siempre una "cristología de la cabeza sin los miembros", es decir, una cristología de algún modo deficiente o anómala. Esto le lleva a examinar la relevancia de la ascendencia de Cristo, primero en la "Iglesia triunfante" y "purgante", y después en la "Iglesia militante" 60 , en un original esfuerzo por contextualizar el dogma de la "communio sanctorum".

Por la relación de Jesús con los santos sabemos que todos ellos (canonizados o no) son "nuestros antepasados en Cristo" y participan ya de la ascendencia de Cristo en diversos grados. Entre ellos se encuentran todos los antepasados africanos que murieron en amistad con Dios. Estos además de ser antepasados por parentesco, lo son también en Cristo ${ }^{61}$. Esta "ascendencia cristiana" de los antepasados es cualitativamente diversa de la propia ascendencia africana tradicional y sobrepasa toda distinción basada en motivos raciales o de cualquier otra naturaleza ${ }^{62}$. En consecuencia, cualquier discriminación entre los seres humanos se opone radicalmente al común parentesco ancestral en Cristo.

Además de la importancia central que tiene la vida de la gracia en el Espíritu ("gracia santificante") para poder vivir completa y auténticamente esa relación ancestral con Cristo y con los santos, Nyamiti subraya también que el parentesco ancestral con "Cristo-Antepasado" implica perseverar en

57 "Those who pretend to have interest in Christ but not in the Trinity are in fact interesed in a false Christ, a Jesus who is not in the Bible - a mere Galilean villager or political revolutionary" ("African Christologies Today", 31). Este es uno de los principales argumentos esgrimidos por Nyamiti frente a la cristología de B. Bujo como se indica más adelante.

58 "Church as Christ's Ancestral Mediation" en J.N.K. Mugambi-L. MAGESA, The Church in African Christianity. Innovative Essays in Ecclesiology, Nairobi 1990, 132 y 137.

59 "Christ is not Head alone; he is Head and members together" (Christ as our Ancestor. Christology from an African Perspective, 49).

60 "Christ shares his ancestorship to the members of the triumphant and suffering churches, namely, to the saints in heaven and purgatory -including the African ancestors who died in him. Through him these saints are the ancestors of the members of the militant church on earth, and of every earthly human being" ("Church as Christ's Ancestral Mediation", 132).

61 Cf. Christ as our Ancestor. Christology from an African Perspective, 125 nota 24.

62 Cf. Ibid., 103-104; "Uganda Martyrs: Ancestors of Mankind": African Christian Studies 2 (1986) 41-66. 
el seguimiento de Jesús mediante un activo compromiso a favor de la paz, la justicia y la liberación integral ${ }^{63}$.

\subsection{Implicaciones prácticas para la eclesiología africana}

La cristología de Nyamiti está estrechamente vinculada con la eclesiología no solamente por las razones teológicas ya apuntadas, sino también por razones antropológicas y pastorales.

La antropología social y cultural ha puesto de relieve la importancia de la vida comunitaria en las sociedades africanas tradicionales. Muchas de las categorías que identifican los roles sociales tradicionales (líder, hermano mayor, maestro de iniciación, sanador, antepasado, liberador, etc.) han sido aplicadas a Cristo por los autores africanos. Es una muestra de que una cristología que quiera hacerse accesible al modo de pensar africano necesariamente tiene que asociar al Redentor con la comunidad, con la comunidad cristiana y con la humanidad en general.

Como ya se ha indicado, Cristo Cabeza está incompleto'sin su Cuerpo, la Iglesia. Ella es de hecho la prolongación de su encarnación en la historia. Desde el punto de vista pastoral, es necesario que la teología académica tenga repercusión en la vida real de las comunidades cristianas, porque, de otro modo, resultará una tarea inútil en la vida de la Iglesia o, al menos, poco provechosa para la gran mayoría. En este sentido la teología debe tratar de dar respuesta a las necesidades concretas de los creyentes. Por este motivo tampoco la cristología puede prescindir de la problemática eclesiológica.

Según Nyamiti, quizás con la única excepción de la "cristología negra" sudafricana, ninguna de las actuales cristologías africanas ha tenido hasta ahora una influencia apreciable en la vida eclesial. Él atribuye esta fractura, en primer lugar, al hecho de que muchas de ellas son todavía en buena medida desconocidas por los propios cristianos. $\mathrm{E}$ incluso allí donde han tenido cierta divulgación, a menudo no se han tomado en serio por las razones que sean. En cualquier caso, él constata que la "teología de los blancos" sigue dominando ampliamente el panorama africano y prueba de ello es que, desafortunadamente, todavía en muchos seminarios o institutos teológicos las cristologías africanas son totalmente desconocidas o simplemente ignoradas. En el mejor de los casos son solamente tratadas como un apén-

63 Cf. "African Christologies Today", 27; "Church as Christ's Ancestral Mediation”, 156-162. 
dice a los tratados cristológicos importados de fuera. La cristología africana es ya una realidad, no meramente unos "prolegómenos". Es cierto que algunas de sus manifestaciones son todavía muy rudimentarias y adolecen de estrechez y superficialidad en lo que se refiere a sus planteamientos, tanto socioculturales como propiamente bíblico-teológicos Pero lo mismo puede decirse de otras cristologías que no son africanas y que sin embargo, curiosamente, se suelen tomar más en serio.

Por otra parte, Nyamiti reconoce deficiencias en el modo transmitir sus contenidos. Los canales a través de los cuales pueden llegar mejor a las comunidades (catequesis, liturgia, institutos teológicos, conferencias episcopales) apenas han sido todavía utilizados. En este sentido aboga por la necesidad urgente de nuevos catecismos africanos que incorporen las propias perspectivas teológicas. Del mismo modo las cristologías africanas deberían incluirse con regularidad en los planes de estudios de los centros y facultades teológicas. Esto es particularmente urgente teniendo en cuenta que sus estudiantes actuales serán los principales encargados de propagar en el futuro la fe cristiana en las Iglesias africanas.

Las cristologías africanas no deberían ser elaboradas desde los despachos de los teólogos, sino desde las comunidades cristianas ${ }^{64}$, en las que la reflexión teológica debe constituir una tarea fundamental. De este modo Cristo podrá ser comprendido a partir de sus problemas y aspiraciones concretas. Por supuesto esto no quiere decir que estas cristologías populares tengan que sustituir, y mucho menos excluir, la labor científica o académica propias del discurso teológico. "Ambas tienen sus específicas potencialidades y limitaciones y, en cuanto tales, se necesitan la una a la otra para complementarse mutuamente de forma provechosa" 65 .

Finalmente, Nyamiti considera que las cristologías africanas sólo recibirán un impulso decisivo cuando, de algún modo, entren a formar parte de la enseñanza magisterial de la Iglesia. Un reto, sobre todo, para las formulaciones doctrinales de los obispos y de las conferencias episcopales 66 .

\footnotetext{
64 En este sentido Nyamiti cita el trabajo de colaboración entre los obispos y los teólogos latinoamericanos, así como la llamada "teología del desarrollo comunitario" representada por algunos obispos africanos que elaboran su teología a partir de la problemática pastoral en la que están directamente implicados.

65 "African Christologies Today", 35.

66 Cf. Ibid., 35-36. Unas expectativas en buena medida frustradas por el Sínodo "romano" sobre África (1993).
} 


\subsection{El debate en torno a la "cristología de los antepasados"}

Completamos la presentación de la cristología de Nyamiti dando cuenta de la repercusión de su modelo entre sus colegas africanos ${ }^{67}$, así como de la acogida que ha tenido en el ámbito de la crítica especializada. En concreto nos limitamos a exponer brevemente la atención crítica que ha suscitado en relación con las posturas cristológicas de dos teólogos contemporáneos: B. Bujo y J. Galot.

Nyamiti admite que su cristología no es totalmente original. Se reconoce en cierta medida deudor de trabajos precedentes inspirados en la teología africana de los antepasados. Y entre ellos cita expresamente algunas de las primeras publicaciones de B. Bujo de carácter cristológico ${ }^{68}$.

En su principal obra, Afrikanische Theologie in ihrem gesellschaftlichen Kontext (Düsseldorf 1986), Bujo cuestiona ante todo el método empleado por Nyamiti. Según él, su cristología parte de los postulados de la "escolástica europea" ajenos al pensamiento africano69. También pone en tela de juicio el interés con que Nyamiti trata de vincular acríticamente la ascendencia de Cristo a un supuesto Adán histórico, cuando, por otra parte, él mismo reconoce que tal origen biológico no es necesario para fundamentar la condición ancestral de Cristo, que sitúa más bien en su naturaleza divinohumana ${ }^{70}$.

Por su parte, Nyamiti considera que la cristología de Bujo minimiza la importancia central del misterio trinitario. Prueba de ello es que se resiste a aplicar el término "Antepasado" a Dios. Una reticencia que, según Nyamiti, no sólo es incomprensible desde sus presupuestos antropológicos, sino que resulta del todo inaceptable desde el punto de vista del razonamiento teológico, y que el autor congoleño no justifica en absoluto. Por otro lado,

67 Sin negar valor a la obra de Nyamiti, algunos consideran mejor el planteamiento de Bujo (cf. J.M. BAHEMUKA, "The hidden Christ in African traditional religion" en Jesus in African Christianity, 12-13). En precedencia otros habían descartado este modelo por considerarlo inadecuado para Cristo. Por ejemplo según Sawyerr, mientraș los antepasados africanos una vez vivieron y ahora están muertos, Jesucristo, una vez muerto, ahora vive. Por eso considera más apropiado referirse a Él como "the elder Brother" (cf. H. SAWYERR, Creative Evangelism, Towards a New Christian Encounter with Africa, 93).

68 Cf. "African Christologies Today", 37 nota 12. Una presentación sintética de los modelos cristológicos de ambos autores se puede encontrar en V. KUSTER, The Many Faces of Jesus Christ. Intercultural Christology, New York 2001, 70-78.

69 "It is impossible to avoid the impression that Nyamiti simply wants to rebuild the echolastic or neo-scholastic, edifice, but using African rather than scholastic or neo-scholastic terminologies" (B. BuJo, African Theology in its Social Context, 68).

70 Cf. Ibid., 94 nota 40 . 
tampoco entiende que rechace su uso con respecto a los santos. De hecho, si Cristo comparte con nosotros su filiación divina, puede compartir también su ascendencia. Y si los santos participan ya de su mediación ancestral, no hay razón para no considerarlos justamente como nuestros antepasados en Cristo $^{71}$.

Además, según Nyamiti, el concepto de "Proto-antepasado", propuesto por Bujo, resulta desafortunado como título cristológico:

Cristo no debe ser denominado nuestro proto-antepasado, si con esa expresión se quiere indicar la singularidad de su ascendencia. De hecho el término proto no sugiere directamente ese carácter único, sino solamente la precedencia entre muchos. Por lo tanto, puede aplicarse a Adán (el proto-antepasado de toda la humanidad). Del mismo modo, se reconoce a S. Esteban como protomártir. Además, incluso si se emplea el término proto-antepasado en referencia al status divino de la ascendencia, el nombre de proto-antepasado correspondería a Dios Padre ya que su ascendencia es idealmente previa a la de Cristo, de quien es su fuente última ${ }^{72}$.

En su recensión del libro de Nyamiti, Christ as our Ancestor. Christology from an African Perspective (Gweru 1984), J. Galot plantea una serie de observaciones críticas ${ }^{73}$. En primer lugar se pregunta hasta qué punto el modelo de los antepasados tiene hoy validez para presentar el misterio de Cristo en el contexto cultural africano. Es decir, si se trata de un lenguaje que sigue estando vigente entre las nuevas generaciones de africanos o si, por el contrario, expresa solamente la nostalgia del pasado tradicional.

Por otra parte, este autor expresa ciertas reservas en cuanto a que el empleo del título de "Antepasado" pueda contribuir realmente a una mejor comprensión del significado de la persona de Cristo y, por consiguiente, a un auténtico desarrollo de la cristología. Según él, algunas características de los antepasados dificultan la aplicación de este título a Cristo. En las tradiciones africanas para entrar a formar parte del mundo de los ancestros es preciso, entre otras cosas, haber dejado mucha descendencia, morir de muerte "natural" y haber llegado a la ancianidad (ser "venerable"). Galot indica que la persona de Cristo no reúne ninguna de tales condiciones. Además, el influjo de la acción de los antepasados se limita al ámbito de sus propios familiares y parientes, mientras que el rol de Cristo como Mediador e Intercesor tiene

\footnotetext{
71 Cf. "African Christologies Today", 38-39 nota 19.

72 "Church as Christ's Ancestral Mediation", 169 nota 8.

73 Cf. Telema 1 (1988) 31-34.
} 
un alcance universal. Finalmente, en su función mediadora, todos los antepasados están totalmente subordinados al Ser Supremo, mientras que Cristo, para la fe de la Iglesia, es el Hijo de Dios: "Dios de Dios, de la misma naturaleza del Padre" (DH 125). Con esta última apreciación ve en la posición del teólogo africano síntomas de un larvado arrianismo.

Ciertamente las objeciones planteadas son graves, pero no insuperables. Y la cristología de Nyamiti da respuesta a todas ellas ${ }^{74}$. En cuanto a la vigencia actual del modelo de los antepasados, Nyamiti señala que, efectivamente, una cristología fundada en elementos culturales desfasados o extinguidos no tendría futuro. Pero este no es el caso. Según él, ante todo, es importante saber distinguir entre el valor permanente universal al que apunta un determinado tema cultural y las manifestaciones externas de dicho valor. De la misma manera que la sanación tiene un reconocimiento y utilidad universal, mientras que las prácticas de sanación, los modos de ejercitar esa función, difieren siempre en el tiempo y en el espacio, también sería equivocado sacar la conclusión de que la veneración de los antepasados se ha desvanecido en un determinado contexto por el mero hecho de que ya no se practica del mismo modo que en otros tiempos. Por otra parte, la experiencia enseña que las sociedades humanas a menudo han perdido e incluso despreciado auténticos valores humanos. La permanencia de los valores culturales depende en buena medida del compromiso activo por mantenerlos vivos en la comunidad.

La vigencia de un determinado modelo teológico está en función del valor cualitativo de la teología que está detrás. Por supuesto que una cristología que se oponga directamente a la doctrina del magisterio no tendrá futuro en la Iglesia católica. Como tampoco lo tendrá una que resulte irrelevante para las necesidades y aspiraciones de la gente.

Nyamiti señala tres requisitos indispensables para la permanencia de un determinado modelo cristológico: el mantenimiento de los valores humanos y religiosos del propio contexto cultural, la integración de esos valores en las condiciones de la vida actual y la relevancia de su propuesta para la mentalidad y las necesidades reales del contexto ${ }^{75}$.

Respecto al título de Antepasado y su aplicación a Cristo, obviamente Nyamiti es consciente de que se trata de un símbolo ${ }^{76} \mathrm{y}$ de que, en cuanto

\footnotetext{
74 Desconozco si hay una respuesta expresa de Nyamiti a las críticas vertidas por el prof. Galot. En todo caso, en sus publicaciones cristológicas posteriores Nyamiti parece tener presentes tales objeciones.

75 Cf. "African Christologies Today", 33-34.

76 Cf. P. TILliCH, Systematic Theology II, London 1978, 84.
} 
tal, exige respetar siempre el principio de la analogía. Desde esta perspectiva es perfectamente legítimo admitir que Cristo ha dejado una "gran descendencia". Gracias a Él somos llamados a la plenitud de una nueva vida, partícipes de la vida de Dios mismo. De este modo el concepto de parentesco se alarga. Cristo es nuestro Hermano-antecesor, porque participa de nuestra naturaleza humana y nosotros pertenecemos a su linaje y somos sus coherederos (cf. $\mathrm{Hb} 9,15 ; \mathrm{Gal} 4,4-7$; Col 1,15-20). En la misma línea se podrían conciliar la identidad de los antepasados y la de Cristo en relación con las otras dos diferencias (la edad y la muerte) apuntadas por Galot ${ }^{77}$. Por último, lejos de todo subordinacionismo, Nyamiti manifiesta explícitamente una escrupulosa fidelidad al dogma de Nicea. Ahora bien, la ascendencia de Cristo procede del Padre como de su fuente original y únicamente por eso puede indicar que es "idealmente" posterior.

\section{Fundamentos para una cristología africana de la liberación en L. Magesa}

\subsection{El rostro liberador de Cristo}

Cualquier interpretación cristiana de la persona de Jesús tiene que fundamentarse necesariamente en la Escritura como Palabra de Dios. Ahora bien, según L. Magesa es necesaria una interpretación contextualizada de la Biblia porque ésta solamente se convierte en "Palabra de Dios" si su mensaje resulta significativo en un contexto concreto y se orienta a promover la vida.

A la luz de la historia pasada y reciente del cristianismo en el África subsahariana este autor advierte la "privatización" de la interpretación bíblica por una minoría de personas o grupos preferentemente blancos, occidentales y de clase media, pertenecientes a las iglesias institucionales o misioneras. La mayoría de la población ha sido excluida de esa tarea. Y sin embargo, ha resultado la más perjudicada por tal privatización, porque, desgraciadamente, en ocasiones la misma Biblia se ha convertido en un instrumento de dominación. Por eso, según Magesa, el significado de la Escritura en África debería ser el principal tẹma a debatir en los foros sobre inculturación o indigenización ${ }^{78}$.

Frente a una hermenéutica privada, que trata de entender el mensaje bíblico "en sí mismo" aunque también de modo inevitablemente ideológico

\footnotetext{
${ }^{77}$ Respecto a valores ancestrales como el liderazgo y la riqueza, un curioso ejemplo ilustrativo de inculturación de la cristología entre los Masaai se puede ver en J. HEALEY - D. SYBERTz, Towards an African Narrative Theology. Nairobi 1996, 76-79.

78 Cf. L. MAgESA, "From Privatized to Popular Hermeneutics in Africa", 28-30.
} 
(consciente o inconscientemente), Magesa aboga por una interpretación "popular" cuyo objetivo ya no es interpretar la Biblia, sino interpretar la vida con la ayuda de la Biblia ${ }^{79}$. Una lectura que conecte la Biblia con la vida no sólo es necesaria, sino que resulta liberadora. $\mathrm{Y}$ en este sentido, cuando la vida está amenazada o es destruida, interpretar la Biblia tiene que significar defender la vida.

En definitiva, según Magesa, la comunidad con sus luchas y su percepción de la realidad debería condicionar, sino determinar, lả orientación de la hermenéutica bíblica. Asimismo, tener en cuenta e incorporar la experiencia social y religiosa de la gente tendría que suponer un proceso continuado de interpretación. En África "no se necesita una nueva Biblia, sino una nueva hermenéutica"80. Es decir, una lectura "africana" de la Escritura.

A partir del análisis de las últimas décadas tras la conquista de la independencia política por parte de los pueblos africanos, Magesa constata que en la situación actual han sido defraudadas en gran medida muchas de las aspiraciones suscitadas por las luchas de liberación. Según él, han contribuido a ello tanto factores externos como internos. Por un lado, a nivel internacional, de la situación de dependencia política de las colonias respecto a la metrópoli, se ha pasado una nueva situación de dependencia económica del hemisferio sur respecto al del norte. Un nuevo desequilibrio socioeconómico que ha sumergido a los pueblos del sur en un estado de "capitalismo periférico" que perpetúa el sometimiento ${ }^{81}$. Pero la segunda causa de la problemática actual de África hay que buscarla en el ámbito de la política local. Es necesario por parte de los pueblos africanos un mayor esfuerzo de transformación de sus propias estructuras sociales para hacerlas mucho más participativas, eficaces y constructivas para el bienestar de cada nación en particular y del entero continente en su totalidad. Por todo ello, desde la perspectiva cristiana "la lucha continua"82.

Para Magesa, en el contexto africano actual, considerar a Jesús como Liberador es mucho más que una bonita metáfora. Es un intento de presentar al único Jesús comprensible y creíble entre las poblaciones campesi-

79 Magesa cita al biblista latinoamericano C. Mesters, cf. Ibid., 31.

80 Ibid., 36. Magesa responde así a la tesis radical del teólogo de Zimbabwe C.S. Banana que propone "re-escribir la Biblia" para Äfrica.

81 "The south is told to work harder, export more, make sacrifices. However for its harder work and more export it continues to get back less or even nothing. For its sacrifices it is slowly strangulated and dehumanized" ("Christ the Liberator and Africa today", 84).

82 " $A$ luta continua" fue el eslógan de la lucha por la liberación de Mozambique, que según Magesa sigue teniendo vigencia en la actualidad tanto desde el punto de vista político como teológico (cf. Ibid., 85). 
nas, los pobres y las nuevas generaciones de jóvenes. Es el Jesús que sigue proclamando la libertad con sus palabras y gestos, a través de la continua auto-revelación de Dios en la historia. El Jesús que pone voz a los sin voz.

Tampoco se presenta a Jesús como el liberador de los privilegiados de la sociedad sólo en sentido metafórico, porque a través de Él, Dios mueve sus conciencias a la conversión denunciando sus injusticias con energía y poniéndose del lado de los pobres (cf. Ex 15,1-21; Lc 1,46-55; 1Pe 5,5). En su vida y ministerio Jesús promovió, como nadie lo había hecho antes, la conciencia de la dignidad del ser humano como hijo de Dios. Se identificó totalmente a sí mismo y a Dios con la causa de todos los oprimidos y rechazados. Y con la misma fuerza llamó a los opresores a cambiar de actitud.

Cuando hablamos de Jesús como liberador, nos referimos a su solidaridad con los últimos y al empeño particular, aunque no exclusivo, de la Iglesia por contribuir a erradicar la pobreza masiva y deshumanizante.

Es una lucha por evitar la muerte irreversible de millones de niños a causa de la desnutrición, las deficientes condiciones higiénicas y la falta de atención sanitaria. Remitimos al ejemplo de la vida de Jesús por hacer una persona mejor y un mundo mejor. Remitimos a su compromiso por instaurar el reinado de Dios, negándose a aceptar como buenas estructuras pecaminosas de dominación religiosa o civil, la corrupción o el tribalismo.

Cristo es el liberador porque es a la vez el fundamento, la inspiración, la razón básica y el garante de la lucha por la liberación de la persona humana, de su desarrollo y salvación, a través de la Iglesia. Por eso nuestra cristología es concretamente eclesiológica: Cristo como liberador, la Iglesia como instrumento agente y articulador de la liberación de Cristo en el mundo. Este es el resumen del contenido de una cristología liberadora ${ }^{83}$.

La encarnación de Dios en Jesús, es decir, en medio de la humanidad y de cada uno de los seres humanos concretos, es, según Magesa, la razón de la inalienable dignidad de toda persona. La kénosis de Cristo (cf. Flp 2,6-11) es el modelo supremo de lo que significa el compromiso y la solidaridad. Pone de manifiesto el valor de la condición humana a los ojos del Creador, tal como la vida y el mensaje de Jesús recuerdan constantemente. Así mismo, la misión del Espíritu de Jesús consiste en mantener vivo ese compromiso divino para con el mundo. Por consiguiente, para los cristianos, el seguimiento de Jesús y la atención a las mociones del Espíritu en ese sentido representan una exigencia ineludible. La tarea consiste en la renovación

${ }^{83}$ Ibid., 87. 
del mundo, en construir puentes de fraternidad y justicia entre las personas y los pueblos.

De acuerdo con los relatos evangélicos, para Jesús las cuestiones "espirituales" no son diversas de las "materiales" cuando lo que está en juego es el bien de la persona. Ante todo, para Jesús tal dicotomía no existe realmente. El propugna la libertad de toda la persona y de todas las personas en la justicia y el amor. Por eso en la versión lucana de las bienaventuranzas Jesús maldice a aquellos que se desentienden de las exigencias de transformación social. A la larga su actitud sólo trae una satisfacción pasajera, que contrasta con el sufrimiento y la humillación de los demás. En cambio, proclama dichosos a los comprometidos en esa tarea, a pesar de sus padecimientos actuales (cf. Lc 6,20-26; Mt 5,3-12).

En la cristología de Magesa ocupa un lugar central el ministerio de Jesús. En concreto su función profética, sacerdotal y real. De acuerdo con la Escritura y la tradición de la Iglesia, Cristo es Profeta, Sacerdote y Rey. Ahora bien este triple munus puede ser mal interpretado si no se sitúa en el contexto de la experiencia histórica de la misión salvífica de Jesús, pudiendo llegar a generar estructuras de opresión y a bendecir abusos de autoridad. Jesús no aparece representado por esos tres atributos de modo convencional ${ }^{84}$.

En cuanto a la profecía, entendida en el sentido de predicción del futuro, El se resiste a las reiteradas presiones de sus discípulos por hacerla manifiesta (cf. Mc 10,35-40 par Mt 20,20-23; Hch 1,6-7). Todavía más llamativo es el reconocimiento de su ignorancia sobre el día del juicio (cf. Mc 13,32 par). Según el contexto de esta confesión (particularmente en las versiones de los evangelios de Mateo y Lucas) lo que Jesús quiere poner de relieve es que la verdadera profecía es la capacidad para descubrir la voluntad de Dios en los acontecimientos presentes (que consiste en amor, misericordia y justicia) y ponerla por obra. Igualmente el sumo sacerdocio de Cristo, tal y como aparece en la carta a los Hebreos, se separa radicalmente del sacerdocio judío. Es el de la víctima que, con su entrega, se ha convertido en el único Mediador, el único camino de acceso a Dios, destruyendo definitivamente el muro que separaba lo divino y lo humano. Tampoco el ejercicio de la realeza de Cristo responde a los patrones tradicionales. Reconociendo su

84 Cf. "Christology, African Women and Ministry", 75-79. Una interpretación de la persona de Jesús sobre la base de estos tres atributos en el contexto de las tradiciones religiosas africanas puede verse en D.W. WARUTA, "Who is Jesus Christ for Africans Today? Prophet, Priest, Potentate" en Jesus in African Christianity, 40-53. 
condición real, más o menos explícitamente, Jesús rechaza toda tentación de usar el poder en beneficio propio (cf. Mt 4,5-6). Y en repetidas ocasiones Jesús muestra como su reinado es de una naturaleza totalmente opuesta a las expectativas humanas (cf. Jn 13,12-17; Jn 18,19-21; Jn 18,33-37).

Por otra parte, segûn Magesa, estos tres atributos guardan una estrecha relación entre sí. Jesús no sólo es Profeta porque escucha y anuncia la Palabra de Dios, sino porque Él es esa Palabra. Y precisamente por ello es también Rey: es a través de su persona como Dios establece su Reinado. Y además lo hace concretamente, de un modo supremo y definitivo, mediante el sacrificio de la vida de su propio Hijo, que se convierte así en Eterno Sacerdote.

Para África, Jesús como liberador es el Maestro que inaugura un nuevo comienzo, un tiempo favorable, "un año de gracia" (Lc 4,19). En Cristo la memoria de los tiempos brutales de esclavitud y colonialismo sigue viva, porque es la memoria de su propio sufrimiento. Sin embargo, también es memoria de salvación que promueve hoy un renovado impulso liberador mediante instituciones civiles y eclesiásticas empeñadas en no tolerar nunca más la degradación y explotación humanas.

Jesús Liberador incansable e incesantemente dice no al hambre, a la tortura, a los ataques a la libertad de expresión, a las detenciones arbitrarias, a los abusos contra el bien común y a la apología del odio interracial con fines políticos. Estas son las cuestiones que esclavizan a África. Ningún Mesías, ni liberador podrá ser reconocido y aceptado como tal hoy en África si no se presenta como adversario, en palabras y obras, de esas inhumanidades u otras parecidas 85 .

Según Magesa, hay que reconocer que con frecuencia la Iglesia ha claudicado en su compromiso liberador. Sin embargo, en su "doctrina social" se pueden descubrir elementos en la línea liberadora de la misión de Jesús para transformar el mundo humanizando las relaciones sociales en la justicia y el amor.

La conciencia de la estrecha relación entre el orden de la creación y el de la redención, tan viva durante los primeros siglos de la Iglesia, se fue desvaneciendo con el paso del tiempo. Sin embargo, desde finales del s. XIX y especialmente a lo largo del s. XX, esta idea de un plan integral de la salvación ha sido retomada por el magisterio. Y es evidente que ofrece importantes orientaciones prácticas para desarrollar una cristología y una ecle-

85 "Christ the Liberator and Africa today", 89. 
siología en clave de liberación. Magesa alude expresamente como ejemplo al Sínodo sobre la justicia en el mundo de $1971^{86}$.

Desde esta perspectiva la Iglesia de Cristo se sitúa en medio del mundo, compartiendo los gozos y esperanzas, las tristezas y angustias de los hombres, "especialmente de los pobres" (GS 1), y animando todo esfuerzo por transformar la sociedad 87 . De este modo continúa el servicio liberador de Cristo en el mundo actual. Por su parte, Cristo puede ser reconocido no sólo como Hijo, sino también como hermano y heraldo de la buena noticia, como sanador y liberador.

\subsection{Dimensión política de la misión de Jesús}

Junto con el pleno reconocimiento de la dignidad de la mujer, la superación de la situación de pobreza deshumanizante que padece el continente africano como resultado de una explotación y opresión secular, constituye hoy, según Magesa, la principal urgencia de África ${ }^{88}$. Por causa de la pobreza mueren allí cada año, literalmente, cientos de miles de personas. Y lo terrible es que, quizás, una muerte rápida es la consecuencia menos cruel de la pobreza. Lo más sangrante es tener que convivir de por vida con la marginación y la desesperación. La cristología en África tiene como interlocutor este mundo de las "no-personas" 89 : de los que "mueren antes de tiempo" y para los cuales la vida ni siquiera se da por supuesta, de los millones de condenados a sobrevivir en medio de la injusticia y la miseria.

Siguiendo el análisis del teólogo camerunés J.-M. Ela y su interpretación de la epopeya del Exodo ${ }^{90}$, Magesa califica la actual situación socioeconómica de África como "contra la vida". En este contexto el mensaje de salvación de ningún modo se puede reducir a su dimensión metahistórica, a

86 Cita también Rerum Novarum y Evangelii Nuntiandi (cf. Ibid., 90-91 y notas 14 y 15). Cf. "Human Rights in the Church in Africa", 103-106; "Has the Church a Rol in Politics?", 82-84.

87 "Human Rights in the Church in Africa", 101. En la obra de Magesa aparece con frecuencia la Constitución Pastoral del Vaticano II como documento de referencia de la moral cristiana en el mundo actual precisamente por su sólida fundamentación antropológica y cristológica. Cf. "Has the Church a Rol in Politics?", 80-81.

88 Cf. "From Privatized to Popular Hermeneutics in Africa", 32.

89 "But perhaps a quick death is the kindest consequence of poverty. The most cruel is a sort of life in desperation, acute marginalization, life for the poor as non-persons. This is what millions of people in Africa experience through the years" (Ibid., 33). Como es conocido se debe a la teología latinoamericana de la liberación la generalización del uso de esta expresión.

90 Cf. J.-M. ELA, El grito del hombre africano, 47-59. 
"ir al cielo" en un sentido espiritualista. Tiene que insistir, sobre todo, en sus dimensiones socio-históricas. Si la vida actual de todos los seres humanos es valiosa a los ojos de Dios, que en Cristo se ha implicado personalmente en su historia, no se puede desplazar sin más su felicidad, su justicia y su libertad, su reconciliación y su paz hacia un más allá desconectado de las condiciones reales del mundo presente. El éxodo de África hoy debe conducir a las personas y a los pueblos del Egipto de la explotación económica y la opresión política hacia una tierra prometida de justicia y libertad. A ello apunta la esperanza de las gentes africanas que confían en un Dios que no se desentiende de su situación, sino que actúa en la historia. Un Dios que atiende el clamor de su pueblo y confunde a los "faraones" de este mundo 91 .

La educación, la alimentación, el crecimiento económico y en la autoestima, no son solamente valores sociológicos necesarios para el desarrollo humano integral. Se presentan también como valores teológicos que indican la solicitud de Dios por sus criaturas. Esto quiere decir que allí donde la imagen de Dios ha sido denigrada, hay que restablecer su dignidad original. De este modo su diseño de salvación será reconocido concretamente como buena noticia.

Por otra parte, pretender que basta simplemente con predicar la Palabra para llevar adelante automáticamente esta tarea de liberación, es una falacia desmentida por los hechos. Es de sobra conocida la desafortunada interpretación fundamentalista del mito de la descendencia de Can (cf. Gn 9,18-29) como un dogma para justificar el tráfico de los esclavos africanos desde el s. XV y la subsiguiente discriminación racial, prácticamente hasta nuestros días ${ }^{92}$.

La historia de la salvación no discurre por caminos paralelos a la historia universal. Según el plan de Dios no hay dos historias, sino una sola. Y su fín último no es "otro mundo" sino un mundo nuevo, es decir, la transformación de "este mundo" en el Reino de Dios. Lo cual significa su liberación. Esto supone una liberación integral de todo aquello que esclaviza a las personas. Liberación que abarca desde las realidades esclavizantes más "espirituales" (odio, resentimiento, codicia, mentira, etc.), pasando por las esclavitudes de tipo "psicológico" (ignorancia, miedo, autodesprecio, complejos de inferioridad, etc.), hasta las más "materiales" (pobreza, domina-

\footnotetext{
91 Para el África contemporánea, según Magesa, algunos de esos faraones tienen nombres propios: empresas multinacionales, FMI y BM (cf. "From Privatized to Popular Hermeneutics in Africa", 33).

92 Cf. Ibid., 34.
} 
ción política, explotación económica, etc.). Por tanto, liberación de toda la persona, tanto a nivel individual como social, y de todos los pueblos, tanto a nivel nacional como internacional ${ }^{93}$.

En la línea de la tradición profética, la enseñanza y la actividad liberadora de Jesús, que deben constituir el fundamento de la enseñanza y la actividad de la Iglesia, incluyen una dimensión "política". Magesa reconoce que se trata de un tema controvertido que siempre desata acalorados debates y posturas beligerantes. Por un lado, hay quienes ven en Jesús una persona apolítica, interesada sólo en el otro mundo y que se resisten a considerar la transcendencia de su mensaje liberador más allá de la esfera puramente religiosa. En el otro extremo, también hay quienes lo identifican como un activista político, contrario al sistema establecido y más o menos vinculado a los movimientos revolucionarios de su tiempo.

Sin quitar importancia a estas cuestiones desde el punto de vista cristológico, Magesa considera que no plantean adecuadamente ni ayudan a resolver el problema fundamental: la influencia de la vida y la actividad de Jesús y su incidencia política en el mundo contemporáneo. Según él, lo decisivo es la repercusión de la enseñanza de Jesús entre su auditorio y las reacciones que provocaron sus acciones liberadoras. En todo caso, resulta un dato incontestable el hecho de que Jesús fue ejecutado en la cruz como un agitador político (cf. Lc 23,2). Jesús rechazó para sí mismo todo poder político (cf. Mt 4,8-10), sin embargo denunció abiertamente los abusos de los que lo detentaban tiránicamente. Magesa señala que esta actitud es particularmente constatable en el evangelio de Lucas (cf. Lc 11,46; 14,12-14). Para él, la misión de Jesús, sin ser una misión propiamente política, tiene incuestionablemente consecuencias políticas ${ }^{94}$.

Por consiguiente, aunque la Iglesia tiene primordialmente una misión espiritual en el mundo, no puede rehuir adentrarse en el terreno político cuando esa misma misión así lo exige. Siguiendo las huellas de su Maestro, se ha hecho especialmente evidente para la Iglesia que su misión en el mundo actual no debe ser política en el sentido de encaminarla a alcanzar cotas de poder e influencia en la sociedad. Esa no es su "misión propia" (GS 76). Sin embargo, en un sentido más amplio, su misión incluye la política

93 Cf. "Has the Church a Rol in Politics?", 75-76.

94 "Still in the direct political arena, Jesus clearly detests the socially harmful role of the Roman stooge Herod Antipas, tetrarch of Galilee and Perea. He refers to him scornfully as a 'fox' because he is abusing his position. But Jesus' disgust is not only directed to corrupt political leaders. It is aimed also against the religious leaders of his time who behaved in the same way. His disputes with the lawyers, Sadducees, Pharisees and the chief priests in the Gospels are well known" (Ibid., 79). 
cuando se trata de defender la dignidad de la persona humana y sus derechos fundamentales como imagen de Dios y templo del Espíritu. Es decir, cuando lo que está en juego es la liberación de la persona humana (cf. GS 9). Para Magesa resulta sorprendente que todavía haya quienes acusan a la Iglesia de "meterse en política" cuando pisa este terreno"

En el ámbito sociopolítico la Iglesia esta implicada en campo de la justicia. Cuando la persona humana es oprimida por estructuras sociales injustas que le privan de su libertad, la Iglesia no puede permanecer callada, ni limitarse a invocar principios éticos con buenas palabras. Tiene que pasar a la acción si quiere ser fiel al mensaje de Jesús. De lo contrario, involuntariamente, se convierte en cómplice de la situación contribuyendo a que las injusticias se perpetúen. En diversas circunstancias y con diversos protagonistas, a lo largo de la segunda mitad del s. XX, la Iglesia ha dado numerosos testimonios de un decidido compromiso en esta dirección ${ }^{96}$.

\subsection{Consecuencias morales: los derechos humanos y la dignidad de la mujer}

La cristología de la liberación propugnada por Magesa inspira y orienta de una forma decisiva sus publicaciones en el campo de la teología moral97. En particular él subraya las implicaciones prácticas que tiene con relación a dos temas absolutamente prioritarios, a su modo de ver, en el actual contexto social africano: la promoción de los derechos fundamentales de la persona humana y la liberación de la mujer.

Como ya se ha indicado en el punto anterior de la exposición, a la luz del mensaje liberador de Cristo, la Iglesia ha incorporado a su "doctrina

95 "Thus Pope John XXIII's encyclical letter Mater et Magistra of May 15, 1961, was greeted with editorial headlines more or less to the effect: "Mater si, Magistra no", precisely because it addressed social issues of poverty and wealth, of justice and injustice. Yet there are areas of the world where the Church sides with those in political power, and this is seldom considered by the same people as involvement in politics!" (Ibid., 80).

96 Cf. Ibid., 82-84. Entre otros ejemplos, con respecto al contexto africano, Magesa cita el compromiso activo de los obispos de la antigua Alto Volta (actual Burkina Faso), el discurso de Pablo VI contra el colonialismo ante el parlamento de Uganda (1969), la denuncia de las atrocidades del gobierno colonial de Mozambique por los Padres Blancos y la actitud de los obispos sudafricanos Hurley (Durban) y Tutu (Johanesburgo) contra la política del apartheid.

97 Cf. "Human Rights in the Church in Africa", 89-110; "Has the Church a role in Politics?", 69-85; "'Sollicitudo rei socialis': The Church Answer to the Current Economic Situation" en Towards an African Christian Liberation, 209-217; The Prophetic Role of the Church in Tanzania Today: Symposium of Five Papers, Eldoret 1991; African Religion: The Moral Traditions of the Abundant Life, Nairobi 1998. 
social" un decidido compromiso en defensa de la dignidad de la persona humana y los derechos humanos tanto individuales como sociales ${ }^{98}$ en todo el mundo. Ahora bien, Magesa se plantea si esos derechos son protegidos igualmente en la práctica dentro del ámbito de las propias estructuras eclesiales, en particular en el contexto africano ${ }^{99}$.

Según él, en los evangelios hay al menos dos episodios que muestran de forma inequívoca el respeto de Jesús por la libertad y los derechos de las personas. Se trata de los episodios del joven rico, transmitido por los sinópticos (cf. Mc 10,17-22 par) y del abandono de muchos de sus discípulos, transmitido por Juan en el contexto del discurso del pan de vida (cf. Jn 6,2271). Ambos relatos muestran una clara actitud antiautoritaria de Jesús. Cada cual es libre de decidir por sí mismo sin imposiciones.

El problema de los derechos humanos dentro de la Iglesia se plantea en el contexto de la Iglesia africana a dos niveles. En primer lugar, tiene que ver con su situación como Iglesia local y sus relaciones con la Iglesia universal. En segundo lugar, con la situación de los derechos de las personas dentro de las Iglesias africanas.

Respecto a las relaciones de las Iglesias africanas con Roma, Magesa considera que no se debe banalizar la cuestión, limitándose a denunciar el "imperialismo romano". Según él, el problema de fondo consiste en situar la cuestión correctamente: no entre las jerarquías eclesiásticas, sino en el ámbito de la Iglesia como comunidad cristiana. Mientras que, desde los años 60, el episcopado en la Iglesia africana se ha ido africanizando paulatinamente hasta convertirse en ampliamente mayoritario en la actualidad, no se puede decir lo mismo todavía del clero local. Aunque en un considerable número de diócesis predomina el clero nativo, otras, en cambio, son todavía muy dependientes de la ayuda exterior. $\mathrm{Y}$ esto tiene una decisiva influencia en aspectos tan importantes para la comunidad cristiana como la formación del clero y de los agentes de pastoral. Es decir, en definitiva, la influencia de la Iglesia africana, a nivel de la base, es todavía mínima dentro de la Iglesia católica.

Por otra parte, Magesa constata un excesivo "temor reverencial" hacia Roma por parte de los obispos ${ }^{100}$. Sólo la libertad aleja el temor. El miedo

\footnotetext{
98 En relación con los llamados derechos económicos, se puede ver su comentario a la encíclica Sollicitudo rei socialis citado en la nota precedente.

99 Cf. "Human Rights in the Church in Africa", 92-97.

100 A propósito del caso del Arzobispo E. Milingo, removido de su sede cuando todavía era titular de Lusaka (Zambia), Magesa escribe: "In fear one cannot usually make rational, well-considered decisions. Yet even if a decision made under such circumstances may be right, it still suffers from the weakness of doing the right thing for the wrong reason. Fear can
} 
siempre condiciona negativamente a la hora de tomar decisiones. Es preciso evitar a toda costa una nueva dependencia religiosa añadida a las otras padecidas en el continente en el ámbito secular. Desgraciadamente se tiene la sospecha de que, todavía hoy, la solución de los problemas de la Iglesia africana suele proceder de instancias ajenas a ella. Una mayor autonomía local, insistiendo en temas como el respeto a la diversidad dentro de la unidad, la colegialidad, etc., son aspectos que contribuirían a salvaguardar los derechos de las Iglesias locales africanas. Incluso el autor sugiere la pertinencia de reeditar para el África negra actual los antiguos concilios norteafricanos ${ }^{101}$, cuyo desarrollo no sólo redundó en beneficio de las comunidades locales sino que, como es sabido, ejerció un notable influjo en el conjunto de la Iglesia universal.

La solución de esta cuestión previa también puede contribuir de modo determinante, según Magesa, a la solución de la cuestión derivada a cerca del respeto los derechos individuales dentro de la Iglesia africana. Porque el estilo de relaciones entre Roma y la jerarquía africana, consciente o inconscientemente, tiene un reflejo en los modos de la relación entre esa jerarquía y los fieles dentro de la Iglesia africana.

Al respecto Magesa pasa revista a tres cuestiones: el disfrute efectivo de los derechos humanos por parte de los fieles, la base de tales derechos y las necesarias reformas en las estructuras que faciliten su protección. El conjunto de los derechos fundamentales de la persona debe ser siempre protegido, también en el ámbito eclesial. Entre ellos, para el contexto de la Iglesia africana, es especialmente relevante el compromiso en favor de la libertad de conciencia, de expresión, de reunión y de asociación. Ello en orden a posibilitar la participación en la toma de decisiones y a elegir el propio estilo de vida sin constricciones. Así mismo, con vistas a proteger la justicia, el derecho a la tutela efectiva por los tribunales y a un juicio justo que respete la presunción de inocencia.

Para Magesa los derechos humanos dentro de la Iglesia tienen un fundamento propiamente teológico: la propia Escritura, la tradición de la Iglesia y el sensus fidelium contemporáneo, siempre siguiendo las orientaciones del derecho canónico y del magisterio eclesiástico (pontificio, conciliar y sinodal). Por otra parte, del dato de que la Iglesia obviamente no es una democracia, no se sigue que tenga que ser una monarquía absoluta que pueda prescindir de fomentar los valores democráticos dentro de sus insti-

therefore never be a moral basis for acting by or within the Church". Los subsiguientes episodios del "caso Milingo", de todos conocidos, han confirmado este diagnóstico.

101 Cf. Ibid., 102. 
tuciones. Unas estructuras eclesiales (parroquias, diócesis, conferencias episcopales) más participativas y transparentes son la mejor garantía para la tutela de los derechos fundamentales ${ }^{102}$.

En la teología de Magesa la liberación de la mujer aparece íntimamente relacionada con la defensa y promoción de los derechos humanos. Entre los autores africanos varones es uno de los que presta mayor atención a este tema en sus obras. Según él, el pleno reconocimiento de la dignidad de la mujer y sus derechos es una de las cuestiones pendientes tanto para la sociedad como para la Iglesia africana actual.

Las consecuencias de la esclavitud primero y de la discriminación racial después han sido padecidas doblemente por las mujeres africanas. Han sido sus principales víctimas no sólo en su condición de africanas, sino también en su condición de mujeres ${ }^{103}$. Por esa razón, "la lucha por la completa emancipación de la mujer en la Iglesia y en la sociedad debe ser considerado un tema central de la teología y la prueba de su espíritu auténticamente cristiano".

Según Magesa, en la experiencia de las mujeres africanas se descubre, en primer lugar, el rostro de aquellos con quienes Cristo mismo se ha identificado de forma privilegiada. El evangelio "real" no es nunca en primer lugar un texto escrito. Antes que nada, es "el cuerpo roto, crucificado y resucitado de Cristo mismo". En consecuencia, en África "el texto del evangelio ha sido escrito en los cuerpos de las mujeres africanas, que como el cuerpo de Cristo, han sido violentadas y crucificadas de todos los modos imaginables"104. Pero, por otra parte, como pone de relieve la teología feminista africana, se puede descubrir también en ellas el ministerio de servicio encarnado por Cristo mismo y presentado como modelo decisivo para sus seguidores (cf. Mt 25,35-40) ${ }^{105}$.

Aunque a lo largo de la historia la interpretación de la Escritura ha estado dominada por una exégesis patriarcalista y sexista, que ha condicionado gravemente la teología ${ }^{106}$, lo cierto es que, en su vida terrena, Jesús

102 Cf. Ibid., 105-106.

103 Cf. "Christology, African Women and Ministry", 79; "From Privatized to Popular Biblical Hermeneutics", 34.

104 "Christology, African Women and Ministry", 85-86.

105 "Despite the marginalization and humilliation they have suffered from the Church throughout history, African women have represented in their life the meaning and significance of the royal, prophetic and priestly qualities of Christ by being the main food suppliers, the organisers and the bonds of unity for the African family and society" (Ibid., 80). Cf. A. NASIMIYU-WASIKE, "Christology and African Woman's Experience" en Jesus in African Christianity, 123-125.

106 Cf. "From Privatized to Popular Biblical Hermeneutics", 34-35; "Christology, African Women and Ministry", 69. 
mostró una clara actitud de cercanía y defensa de las mujeres en la línea de su opción preferencial por los pobres y marginados (cf. Mt 9,20-22; Mc 7,2530; Lc 7,36-50; Lc 10,38-42; Jn 4,1-42; etc.). Por otro lado, es indiscutible que, aunque no pertenecieran al grupo de los Doce, las mujeres formaron parte de su movimiento al mismo nivel que los varones. Siguieron a Jesús hasta la cruz, participando de algún modo en su dolor y sufrimientos. Además, no sólo fueron los primeros testigos de la resurrección, sino que la figura de María Magdalena desempeñó con bastante probabilidad un rol importante en las primeras comunidades postpascuales.

Todo ello debe llevar a entender que el predominio masculinizante en las instituciones eclesiales es un "escándalo persistente que oscurece la presencia simbólica de la Iglesia como sacramento de comunión entre Dios y la humanidad"107. Si la re-presentación de Cristo ("in persona Christi") 108 es un elemento determinante para el ministerio ordenado, no se entiende que se excluya de él a las mujeres. Una estructura ministerial exclusivamente masculina difícilmente puede representar la totalidad de la Iglesia. Para Magesa, está todavía por explorar una teología del significado del cuerpo en la vida de Jesús y su relación con el ministerio de la mujer en la Iglesia.

La fidelidad de la Iglesia a sí misma en cuanto sacramento de comunión y cuerpo de Cristo, tiene que implicar el rechazo del carácter androcéntrico de algunas de sus estructuras para que pueda reflejar la comunión de toda la humanidad, masculina y femenina, en Dios.

\section{Conclusiones}

El redescubrimiento del rostro de Cristo que ofrecen las actuales cristologías africanas está contribuyendo a recuperar aspectos de la persona y de la obra de Jesús no suficientemente valorados o tácitamente ignorados en la evolución del dogma cristológico. Por ejemplo, elementos como las genealogías o la actividad curativa y exorcista de Jesús.

Sin embargo, en el uso de los títulos cristológicos no hay que perder nunca de vista el principio de la analogía: toda semejanza implica una desemejanza mayor (cf. DH 806). Como Señor, Mesías e Hijo de Dios, también

107 "Christology, African Women and Ministry", 87.

108 "In as far as they give life where there is none, in as far as they embody the qualities and the message of Jesus the Christ in any way in their life experience, it is difficult to see how women cannot stand in persona Christi" (Ibid., 88). 
Maestro de iniciación, Liberador y Antepasado son solamente símbolos, siempre imperfectos e inadecuados, que sirven para expresar lo que representa la persona de Jesús y su obra salvífica en las categorías del lenguaje propias de un contexto cultural determinado. Y sólo resultan significativos desde ese registro lingüístico, es decir, entendidos en ese sentido análogo.

Por otra parte, tampoco hay que olvidar que cualquier título al ser aplicado a Jesús experimenta a su vez un proceso de reinterpretación a partir de Jesús mismo, adquiriendo así su valor propio y original. Porque el criterio decisivo para acceder a su significado no lo señala el patrimonio cultural del que han sido tomados, sino el mismo Misterio de Cristo de quien reciben una luz nueva. Así Jesús es el Liberador de toda enfermedad y esclavitud, personal o social, más allá de las prácticas de cualquier nganga; y es el Hermano Antepasado original, fuente de vida divina, de quien descienden y de quien reciben su fuerza benefactora todos los living dead.

Por este camino la teología africana está produciendo ya una cristología en contexto "ascendente" y narrativa que redimensiona aspectos centrales del misterio de Cristo frecuentemente relegados o considerados superficialmente por muchas de las cristologías "occidentales". A promover este empeño común contribuyen de forma destacada los trabajos de Nyamiti y Magesa, los dos teólogos tanzanos a quienes hemos dedicado estas líneas. Evidentemente sus ensayos son un fiel reflejo de sus propios posicionamientos teológicos. Ahora bien, al mismo tiempo, ambos reconocen la necesidad de un diálogo abierto entre la perspectiva de la inculturación y la de la liberación en el empeño común por construir una cristología genuinamente africana. Algunas de sus publicaciones ${ }^{109}$ auguran, además, un prometedor intercambio entre sus respectivos modelos.

R. SALA

109 Cf. C. Nyamiti, "Contemporary Liberation Theologies in the light of African Traditional Conception of Evil": Studia Missionalia 45 (1996) 237-265; L. MAGESA, "The Present and Future of Inculturation in Eastern Africa" en P. TURKSON - F.J. SERVAAS WIJSEN, eds., Inculturation: Abide by the Otherness of Africa and the Africans, Kampden 1994, 57-71. 